San Jose State University

SJSU ScholarWorks

Master's Theses

Master's Theses and Graduate Research

1996

\title{
The decision-making process of all-news radio and how it affects the quality of content
}

Susan Faller-Mitchell

San Jose State University

Follow this and additional works at: https://scholarworks.sjsu.edu/etd_theses

\section{Recommended Citation}

Faller-Mitchell, Susan, "The decision-making process of all-news radio and how it affects the quality of content" (1996). Master's Theses. 1324.

DOI: https://doi.org/10.31979/etd.x3ua-7vg2

https://scholarworks.sjsu.edu/etd_theses/1324

This Thesis is brought to you for free and open access by the Master's Theses and Graduate Research at SJSU ScholarWorks. It has been accepted for inclusion in Master's Theses by an authorized administrator of SJSU ScholarWorks. For more information, please contact scholarworks@sjsu.edu. 


\section{INFORMATION TO USERS}

This manuscript has been reproduced from the microfilm master. UMI films the text directly from the original or copy submitted. Thus, some thesis and dissertation copies are in typewriter face, while others may be from any type of computer printer.

The quality of this reproduction is dependent upon the quality of the copy submitted. Broken or indistinct print, colored or poor quality illustrations and photographs, print bleedthrough, substandard margins, and improper alignment can adversely affect reproduction.

In the unlikely event that the author did not send UMI a complete manuscript and there are missing pages, these will be noted. Also, if unauthorized copyright material had to be removed, a note will indicate the deletion.

Oversize materials (e.g., maps, drawings, charts) are reproduced by sectioning the original, beginning at the upper left-hand comer and continuing from left to right in equal sections with small overlaps. Each original is also photographed in one exposure and is included in reduced form at the back of the book.

Photographs included in the original manuscript have been reproduced xerographically in this copy. Higher quality 6" $\times 9$ " black and white photographic prints are available for any photographs or illustrations appearing in this copy for an additional charge. Contact UMI directly to order.

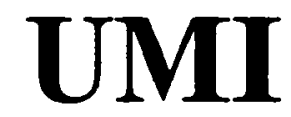

A Bell \& Howell Information Company 



\title{
THE DECISION-MAKING PROCESS OF ALL-NEWS RADIO AND HOW IT AFFECTS THE QUALITY OF CONTENT
}

\author{
A Thesis \\ Presented to \\ San Jose State University \\ In Partial Fulfullment \\ of the Requirements for the Degree \\ Master of Science
}

The Faculty of the School of Journalism and Mass Communications

by

Susan Faller-Mitchell

August 1996 
UMI Number: 1381435

UMI Microform 1381435

Copyright 1996, by UMI Company. All rights reserved.

This microform edition is protected against unauthorized copying under Title 17, United States Code.

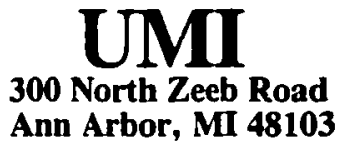


(c) 1996

Susan Faller-Mitchell

ALL RIGHTS RESERVED 
APPROVED FOR THE SCHOOL OF JOURNALISM AND MASS COMMUNICATIONS

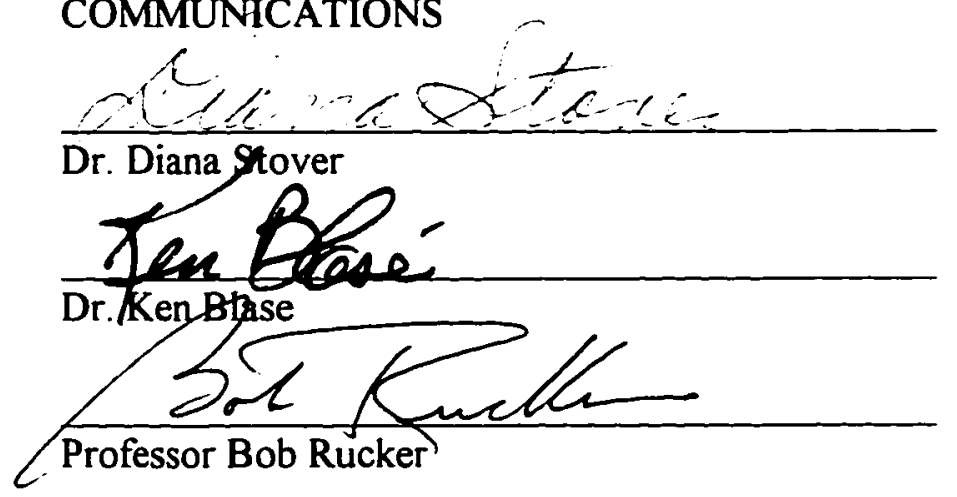

APPROVED FOR THE UNIVERSITY

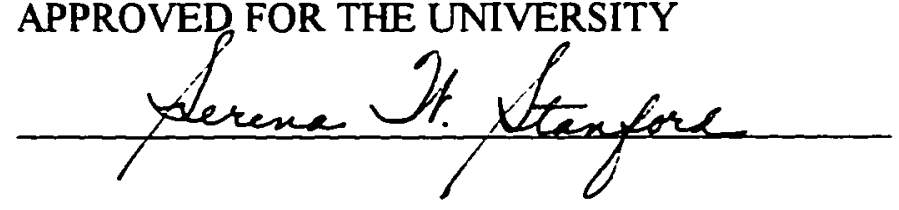




\title{
ABSTRACT \\ THE DECISION-MAKING PROCESS OF ALL-NEWS RADIO AND HOW IT AFFECTS THE QUALITY OF CONTENT
}

\author{
by Susan Faller-Mitchell
}

This thesis was a participant-observation study of two all-news radio stations, KCBS in San Francisco and KMPH in Fresno. The 1995 observation involved 21 weekdays at KCBS and 5 weekdays at KMPH. The study examined the decisionmaking process and how institutional, organizational, and individual constraints affected the quality of the news product and included interviews with reporters, editors, anchors, and management. A content analysis of three one-hour recorded news blocks was done to augment observations of news content diversity. This study provides insight into radio news quality since deregulation in 1981. Radio journalists face many of the same constraints as their print and television counterparts. Radio journalists live with the station's economic limitations and ratings. The development of organizational routines, which sometimes become crutches, limit the innovation of reporters. Establishment of these routines and the socialization within the newsroom result in a factory atmosphere in all-news radio. 


\section{Table of Contents}

$\begin{array}{lll}\text { Chapter } & \text { Page }\end{array}$

I Introduction .................... I

II Literature Review . . . . . . . . . . . . . . . . . . 7

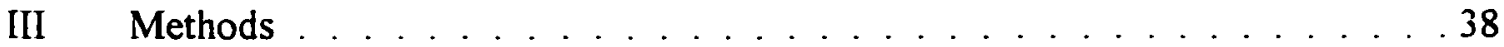

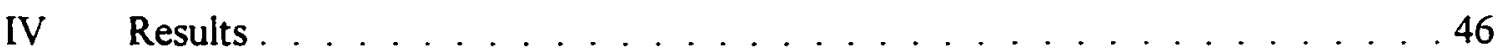

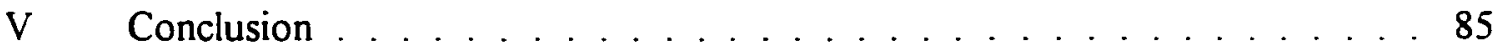




\section{List of Figures}

Figure $\quad$ Page

$1 \quad$ KCBS Morning Drive . . . . . . . . . . . . . . . 51

2 KCBS Noon Drive . . . . . . . . . . . . . . . . . 52

$3 \quad$ KCBS Afternoon Drive . . . . . . . . . . . . . 53

$4 \quad$ KMPH Morning Drive . . . . . . . . . . . . . . . . . . . . 54

$5 \quad \mathrm{KMPH}$ Noon Drive $\ldots \ldots \ldots \ldots \ldots$

$6 \quad$ KMPH Afternoon Drive . . . . . . . . . . . . . . . . . . . . . . 


\section{CHAPTER I}

\section{INTRODUCTION}

Throughout the history of the United States, journalism has been the target of criticism. But, even the toughest critics maintained a desire for some sort of objective information source free from government constraints. What many people fail to realize is that there are many subtle constraints that can be just as damaging. This study looked into the constraints affecting the decision-making process for all-news radio.

White's (1950) gatekeeper study highlighted the flow of information past the editor of a newspaper. Whitney and Becker (1982) updated White's results by demonstrating how gatekeepers for the national wire services wielded more influence by choosing what information to send out to news organizations. Bailey and Lichty (1972) reviewed how the organization at NBC acted as a gatekeeper for a major television story during the Vietnam War. Very little research has been done with a focus on radio. Those studies that include radio tend to place a major emphasis on television.

A secondary focus of this study was the quality of the news content. Critics and casual observers have long complained about the quality of the journalistic product. In 1981, the Federal Communications Commission deregulated radio, and stations were no longer required to produce a certain amount of news programming as a public service. The effect of these changes has had little more than a cursory review by professionals within the industry.

Evaluating the quality of news content requires an in-depth review of accuracy, objectivity, diversity, format, and creativity. The 1947 Commission on Freedom of the 
Press defined the goal of journalists as one of providing "a truthful, comprehensive, and intelligent account of the day's events in a context which gives them meaning" (p. 21). In more recent years, Shoemaker and Reese (1996) noted a variety of organized efforts to improve quality including Accuracy in Media, Fairness and Accuracy in Reporting, and the National Coalition on Television Violence (p. 186).

There are also those who have come from within the journalistic field who have commented on the quality of the news product. Bagdikian (1992) wrote about the danger of media monopolies in his book. The Media Monopoly. His argument is that powerful media corporations are buying up news outlets around the world and doing away with the concept of local competition. Proven formats are put in place and diversity is shut out. Bagdikian stressed that the economic factor of risk taking is considered dangerous at the organizational and institutional levels. Few news managers are willing to try out innovative formats and styles of coverage because of the immense amount of money tied to each ratings point. Economics, Bagdikian argued, has forced owners of news operations to run those operations like a business with a focus on the bottom line. The results are fewer reporters and fewer resources. This starts to affect the quality of the product, but since everyone is doing the same thing, few journalists look beyond their colleagues for critique.

The economic factor is even felt at oppositional news stations such as KPFA-FM in Berkeley, CA as studied by Eliasoph (1988). She found that organizational and economic factors affect content more than the choices made by journalists. She found that determining news content was primarily based on the opinions of fellow journalists at the 
station and the views of superiors. In fact, after two years on staff, Eliasoph found that journalists at the oppositional station developed many of the same routines as those in the mainstream media. However, the content was presented from a different angle.

Journalists, as demonstrated by Breed (1955) and Tuchman (1972), have gone through the socialization of the newsroom and have developed behaviors to cope with the organizational constraints placed upon them. Sigal (1973) wrote that journalists learn their geographic and functional roles within the organization. The individual journalist also faces the economic reality of needing to maintain his or her position within the organization. Therefore, Bagdikian (1992) argued, there is little concerted effort to change the organizational constraints that limit the quality and diversity of news. Fallows (1996) wrote that the prevalence of simplistic stories and coverage of pseudo-news events results in shallow news content and, in effect, inaccurate reporting. Fallows noted that journalists need to immerse themselves in a story and take time to find the truth: "Through the process of listening, learning, testing assumptions, and letting themselves be surprised by new evidence, reporters decide what they think is true enough to write. This cannot be done with the assembly-line interviews of the newsmagazine shows" (p. 58). Epstein (1973) noted that journalists and management hesitate to open the door to evaluation: "News executives hold that there is no need to analyze the way in which a news organization selects material and puts together a news program because, they argue, the process has little if any effect on the end product - news is news" (p. 10). Fallows (1996) has called on the media to take an honest look at the industry and recognize where mistakes are being made and why. Beyond recognition of journalistic faults, Fallows 
encouraged those in the industry to take a more proactive approach to reporting that would invite people to take part in solving society's problems rather than simply presenting those problems as a daily ncws dict.

This case study examined how organizational constraints affected decision-making on news content at a major market all-news radio station. KCBS in San Francisco, and compared the data to a shorter field study at a medium market all-news radio station, KMPH in Fresno. The study was conducted in the spring and summer of 1995 . The participant observation at KMPH lasted one week. A three-week field study was conducted at KCBS. The week before the actual field work began, the researcher spent a brief period at the station becoming acquainted with the staff and procedures. This study examined the organizational level of the radio stations, noting the amount of resources provided to news personnel, the organization of the newsroom, the format of the station, and the emphasis on news conventions including objectivity, accuracy, and diversity of news coverage. The qualitative study also examined whether the routines set in place by journalists to cope with organizational and institutional constraints limited the diversity of news content and reduced the quality of news coverage. Other economic, political, and social influences at the institutional level were also examined such as competition for market share. Through observations and interviews, analysis was also done at the individual level involving the reporters and editors at the two radio stations.

One framework for the study of broadcast journalism uses a factory model. Bantz. McCorkle, and Baade (1980) saw the underlying structure of the news operation as having the same characteristics of any other organization producing a product. Bantz et al. saw 
broadcast news as having the organizational and environmental pressures that foster routinization of newswork. Five factors were highlighted in this study: a) the nature of news staffs, bj technoiogical deveiopments, c) the impact of news consuitants, d) considerations of profit, and e) constraints on the organization's product. Simply put, Bantz et al. wrote that news is put together in an assembly line fashion with little ownership and pride by those who are a part of the process. The reporters observed by these researchers showed more characteristics of a factory than a professional organization. Bantz et al. noted that "the trends in television news--the turnover of newsworkers. the influence of consultants, the producer supervision, the increased technical sophistication, increasing organizational size, and the emergence of the news as a profit center--have contributed to local television news' development of a highly constrained, routinized approach to news" (p. 65).

The factory model was used as the theoretical basis for this study with aspects from the work of Drew (1972) on role expectations and Soloski (1989) on professionalism in the newsroom. Journalists who believe management expects them to be just another reporter on the assembly line show little initiative toward innovative writing and a search for the truth of the day's events. Many of the routines used by journalists to cope with the job of putting together a news program are established by management as a way to better control the station's employees. Although routines are necessary to manage the unpredictable world of news, the reliance on such routines tends to limit the journalist 's ability to get the full context and truth of a news story. Tuchman (1978) wrote that "news organizations routinize the processing of seemingly unexpected events by typifying them 
along dimensions that reflect practical tasks associated with their work" (p. 117). The research question for this study was whether institutional, organizational, and individual influences inhibited the role of the broadcast journalist in providing an accurate picture of newsworthy events. Institutional influences focused primarily on competition and the ratings game within the radio broadcast industry. The organizational influences included routines set up to help journalists cope with the ever-changing world of news. Such routines included deadlines established to meet the needs of the format of the station, the presentation style which dictated such things as story length, and the coverage of pseudonews events. The individual influences included media agenda-setting and how reporters tend to follow each other rather than encourage innovative coverage. Objectivity and how it influences the news content was also covered under personal influences. 


\section{CHAPTER II}

\section{LITERATURE REVIEW}

This literature review focuses on organizational constraints in broadcast journalism, especially radio news operations, and how the routines developed by journalists to cope with these constraints affect the quality of news coverage. These constraints may include economic limitations, format design, and personnel preferences. Routines are defined as the procedures developed by news people to provide a somewhat predictable flow of news in the ever-changing world of current events complicated by the various constraints placed upon them by management. The factory model framework provides a picture of news being manufactured with the predictable flow of news moving through a newsroom just like a conveyer belt through a factory. Clearly, news organizations develop routine behaviors to cope with the fast-paced world of news. Such behaviors might include providing only part of the story to get some information on the air quickly. These behaviors are a viable part of a quality radio news broadcast, but a routine developed to cope with a managerial constraint can also reduce the quality of news content. An example of such a routine would be cut-ins from the newsroom using phone calls from unverified witnesses because there are not enough reporters to cover a stcry in person. Diversity of news content focuses on the variety of news stories offered to the audience and the length of time between repetition of major stories. This variety covers the type of story (i.e. political, crime, feature) as well as the angle taken by the reporter in writing the story. At issue is whether journalists and their organizations look for ways to

provide news for the diverse listening audience. Berkowitz (199l) noted that "as long as a 
media organization strives to remain financially viable, resources will be constrained to some extent, so that news selection results from a precarious balance between news judgments and resource allocations" (p. 246). This chapter reviews the literature concerning how institutional, organizational, and individual influences affect the news content in radio. Within these categories, the following areas will be discussed: radio deregulation, competition, market-driven journalism, the structure of news, the nature of news, pseudo-news events, routines, deadlines, presentation, media agenda setting, the definition of news, and objectivity.

\section{Institutional Influences}

\section{Radio Deregulation}

During the early years of broadcasting, the Federal Communications Commission (FCC) wielded a lot of power over stations. Even small and medium-market stations provided news and information programming to keep their licenses. In 1981, the FCC deregulated radio, and media critics have been evaluating news programming to determine if the quality of news content has been affected by deregulation. Without the requirement to provide news, the concern was that most stations would drop that segment of programming because of its expense. Early reviews in the RTNDA Communicator indicated that as of mid-year 1982, very few stations had changed their format to eliminate news. However, nearly a decade later, the change is more evident. In the September 1990 edition of Broadcasting, figures are cited that indicate a move away from news on

FM stations and an increase in the AM newstalk format. A more difficult issue to quantify is the change in news style. Network presidents are quoted in Broadcasting in 1990 as 
saying the push in the mid-1980s was toward lifestyle news. This format was based on the opinion that listeners wanted to hear news that directly affected their lives. This resulted in cutbacks on the coverage of news that dealt with abstract issues and focused on more simplistic, close-to-home news. This style of news coverage is easily produced within a factory model framework. A few years later, network presidents began to hear from listeners that they wanted to get back to what they term real news or news with more substance.

\section{Competition}

One of the strongest external and internal forces affecting broadcast news content is competition. These forces come from the industry as a whole, as well as from within the organization. Competition is set in place by the organization so that the atmosphere surrounding a news operation is charged with the competitive spirit. This atmosphere and the players who function within it then perpetuate competition so that it becomes more than simply a behavior to produce the news product but rather a routine that may result in lapses of journalistic quality. Ehrlich (1992) wrote that the use of rituals can be used with the competitive ideology. Broadcast journalists, Ehrlich wrote, use "competition as a set of enacted rituals which help television newsworkers manage professional uncertainty and which also help legitimate the status quo" (p. 21). Some of the rituals include monitoring competing broadcasts, listening to police scanners, and pushing each other to get the story first if not exclusively.

The question of the current state of news competition has been studied by many. Gale Research (1990) noted that very few large markets have any competition within the 
print news market. However, there is still a lot of competition within the broadcasting industry--a competition that appears to be growing with the expansion of cable television. In broadcasting, radio reporters compete with reporters from other radio stations as weil as with television reporters. Radio executives maintain radio still has the advantage of immediacy and convenience. Brad Kalbfeld, who is with Associated Press Radio, is quoted in the 1991 edition of Broadcasting as saying that "radio is the medium that provides the greatest opportunity for instantaneous updates" (p. 24). Kalbfeld and others noted the ability of radio journalists to get their stories on the air as easily and quickly as picking up the phone. Radio also has the advantage of being media that people can monitor while doing something else; the audience is often engaged in another activity, such as driving, while still listening to the radio.

The concept of competition is one in which the players strive to reach their potential. With this in mind, one would think competition would improve the quality of news; however, many studies have shown that the push of competition has actually reduced the quality of news content within the industry. Eisenberg (1990) analyzed the competition between major television stations in the San Francisco Bay Area and tried to pinpoint when KGO went to a format that pushed infotainment. The formula developed by the news consultants of the early 1970s "relied heavily on fires, violent crimes, sex scandals, and the chemistry of news anchors who could schmooze well with one another on camera" (p. 68). This concept became known as happy talk and spread to other stations hungry for ratings points. Newsworkers are often quoted as saying they oppose the level of competition that now pushes them beyond their ethical boundaries. In 1990 
long-time San Francisco Television News Anchor Evan White told the San Francisco Focus that his profession has become a highly competitive business in which journalism has taken a back seat to entertainment. This dilemma of value balancing is discussed by Steele (1987) as he pointed out the contradictory values of competition and organizational expectations with journalistic integrity and ethics. Steele wrote that, "while it can be forcefully argued that the competitive spirit prompts quality journalism, an abundance of evidence suggests that competitive fervor leads to unethical actions" (p. 12). As editors of newspapers compare their stories with those of other papers, television and radio executives monitor other broadcasts to see if their people missed anything. Reporters remark that this kind of pressure from the organization makes it difficult for them to follow ethical values (Steele, 1987). In the research done by Breed (1955), newsworkers found avenues to get around the organizational policies. In the same vein, newsworkers within the broadcasting industry are looking for ways to maintain ethical values. One photojournalist quoted in Steele's work (1987) said he never shoots blood at the scene because the editors would surely use it. Although the newsworkers often have a certain amount of autonomy while in the field, the organization still holds the key to deciding which reporters cover the big stories. Reporters recognize that to warrant better salaries, they have to have major story coverage. This financial constraint pushes the journalist to fall in line with organizational expectations for competition with other stations. Market-driven Journalism

The question of whether news quality can be maintained as a market-driven commodity was analyzed by McManus (1992). It is noted that news, especially broadcast 
news, is a commodity only partially funded by the audience. The bulk of revenues comes from advertising and, as McManus noted, "national advertisers are paying, not for news quality, but for audience quality and quantity" (p. 789). The motivation for news operations is to prove that the content provided will gain a large audience, and this has traditionally been the basis for the ratings game. McManus wrote that "advertising's subsidy makes a definition of quality based on popularity more profitable than one based on less widely shared professional or craft standards" (p. 790). Along with affecting newsworkers' professional standards, McManus noted that information about segments of the population not considered prime targets of advertisers are ignored. In essence, a major source for diversity within the newscast is cast aside. Berkowitz (1990) noted that the broadcast format can be linked to an organization's financial constraints. Berkowitz found that the stories that had the greatest chance for airing were those that dealt with concrete issues such as crime and disasters. These are also usually one-shot stories that require little time, effort, or specialized knowledge on the part of the reporter. The factory model can be employed. A common line among journalists is to just change the names because the facts of a current story are little different from the facts of a story covered in the past. Fallows (1996) used a few examples to highlight this routine to cover the simplicity of a story: "It is sexier and easier to write about Bill Clinton's 'positioning' on the Vietnam issue, or how Newt Gingrich is 'handling' the need to cut Medicare, than to look into the issues themselves" $(1996$, p. 27). From a financial point of view, it takes a lot less money to produce a newscast full of these types of stories as compared with the work and time involved in investigative pieces. 
Eisenberg (1990) wrote that the knowledge of how to turn news operations into money-making centers has resulted in steep declines in professional values: "News is no longer driven by a desire to serve but a need to make money" (p. 66). This fecling is backed up by reporters and anchors such as San Francisco's Anna Chavez of KRON who is quoted by Eisenberg as saying that the news has simply become "one of the vehicles for Cap Cities/ABC to make money" (p. 66). Executives in the field more recently have discussed their concern with shrinking ad revenue and the push to cut staffing and look for other ways to fill the gap. Radio and Television News Directors Association members have been considering ideas such as pooled coverage of events ("All the news," 1991). In the 1991 article, radio news operations were reported in financial difficulty as well. In the midst of all the discussion on finances, the journalist may try to separate himself to maintain his professional values.

The results of economic issues are felt at all levels of the organization. In some cases, staffing and salaries are adjusted. This has a domino effect in that deadline pressure increases with fewer reporters to cover the same amount of news, resulting in potential problems with objectivity and accuracy. Journalists may be called on to do commercial announcements. Stations may choose a format that uses network programming in place of local news stories. Such changes are not restricted to the local news operations. Epstein (1975) discussed the fact that network news is just one part of the television network and must live within a budget that allows for a significant profit margin. What the viewer may see as a personal distortion or bias on the part of the reporter may in fact have its roots much higher in the organization. As Epstein explained: "the most persistent distortions in 
network news flow not from the choice of newsmen or even producers, but from the survival requisites of the networks" (p. 209).

\section{Organizational Influences}

\section{Structure of News}

To develop an outline of the structure of broadcast news, it is essential to begin with a definition of the structure of news. Roshco (1975) wrote that news reflects or mirrors social reality. In this view, news is dependent upon the social structure and, for the definition of news to change, society's definition of news must change. Another approach to the structure of news is one in which the players are more active. In the interpretive approach, newsworkers invoke, apply, and define the norms of society, and in so doing, help to define news. Tuchman wrote "this approach argues news does not mirror society. It helps to constitute it as a shared social phenomenon" (1978, p. 184). McManus (1994) compared the effort involved in disseminating news to the effectiveness of the headlamps on a car: "Society's headlights have to shine farther and more broadly than ever before, and their beams must be bright enough for us to see our options and their consequences" (p. xi). Newsworkers have traditionally carried the burden of getting out the information to the public. However, as populations grew and mass media technology became more complicated, the idea of presenting an accurate picture of what is news to the mass audience has become a formidable task. Although technology has allowed for an increase in both speed and quantity of information that can be processed. the journalist is faced with the dilemma of how to decide which items are the most newsworthy. With this level of responsibility in the dissemination of knowledge, the 
journalist should be aware of the various obstacles to presenting a quality newscast.

Berkowitz (1990) noted that many researchers who have studied the issue of newscast quality have conciuded that news-related values are a stronger determinant of content than show business-related values. It has also been determined that market size has a tendency to dictate the type of news content. Berkowitz wrote that "some studies, however (e.g., Carroll, 1989), have found differences among media organizations in different market sizes, with major market stations likely to devote more attention to soft news than medium - or small - market stations" (p. 56). Fallows (1996) focused much of his writing on the coverage of politics. He wrote that the majority of political news content focused on the race for office rather than the issues or qualifications of the candidates. Noting the work of those promoting public journalism, Fallows wrote: "Editors and reporters at these news organizations attempted to produce coverage that would make people feel re-connected to the public life of their community" (p. 255). To accomplish this goal, these journalists researched various issues to determine which were most important and had the greatest impact on the future. Tuchman (1978) noted that the news industry actually limits knowledge by helping to maintain the status quo. Organizational constraints such as deadlines, ratings competition, budget limitations, the use of subsidized programs, and format restrictions, result in the maintenance of the status quo.

It is essential to review three levels of analysis in the study of mass communications. The individual reporter is at the first level; at the second level, there is the organization; and at a still higher level is the institution or news industry. In the analysis of White's (1950) classic gatekeeper study, Whitney and Becker (1982) found that 
influences on news content are traced farther up the chain of command. It is not simply the reporter or editor deciding what is newsworthy. Ettema and Whitney (1987) wrote aboul the importance of examining several leveis of analysis. At the institutional level is the economic structure within which the mass media must operate and survive. Ettema and Whitney wrote that journalism is also a tool for social control, adding that "its primary effect is either to direct and shape political dialogue or to limit diversity of opinion and information that is expressed" (p. 763). The organizational level highlights bureaucracy of news production, routines and conventions, and management. Professionals at this level argue that what they do is not constraining news content but rather selecting news content. Finally, at the individual level, the issue is whether the personal attitudes and values of the reporters affect the presentation of the news. It is also important to note how professional journalists work through the organizational and institutional constraints and still present some kind of creative and unique news coverage.

The Nature of News

Although journalists have some degree of autonomy and independence, they are still working within the constraints of an organizational system. In defining the reporter as an organizational man, Sigal (1973) described the functional and geographic lines of a news operation including the various roles of reporters, editors, and publishers. Although it may be easier to focus criticism on reporters for how they write their news stories, Sigal wrote that "organizational processes and bureaucratic politics account for more of news content than, say, the political proclivities of the individual newsmen. In short, what newsmen report may depend less on who they are than on how they work" (p. 5). Epstein 
(1975) also noted that, even if news people are personally fair and unbiased, an organizational tilt can come through in the news content: "a television network 'tilted' in a consistent direction because of the way it is organized will also tend to fayor certain types of stories over others, no matter how fair the newscaster might be" (p. 200). Bailey and Lichty (1972) examined how the various people within a network news organization make decisions about what will eventually air. The reporter in the Bailey and Lichty study was only the first of many gatekeepers. Using the factory model framework, Bailey and Lichty wrote that the reporter on the scene quickly loses ownership of the news product: "Informal communication-decision networks operated within NBC to reduce the individuality of decision" (p. 229). Many of the people involved in the story shared the same journalistic ideas about the importance of the story. Bailey and Lichty noted that "the journalistic subculture crosses formal organization boundaries to influence gatekeeping decisions" (p. 229). Epstein (1973) wrote that "to describe network news as mirroring events thus necessarily involves seriously neglecting the importance of the chain of decisions made both before and after the fact by executives and newsmen, or, in a word, the organizational processes (p. 25). In White's (1950) study, the organization was designed on a linear line with various gatekeepers along the way determining news content. Using the organization as a conceptual model, Shoemaker and Reese (1996) suggested a hierarchical design in which the organization as a whole is the gatekeeper. The various levels begin with the individual in the center, followed by larger circles encompassing media routines and finally the organization. The organizational layout of the newspaper newsroom places the editor in the key role for determining news content. 
Television stations also have organizational roles, but the check and balance role of editors, especially at the local level, is not as widely used to determine news content. For radio, there are even fewer opportunities to check over stories before going on the air to determine whether they fall within the policies of the station. However, this is not to say that there is less control placed on broadcast journalists. Berkowitz (1991) interviewed several reporters who saw their personal news judgment as important in the development of the newscast, but they also recognized the constraints they faced in doing their work. Resource constraints were somehow compensated for in the case of extremely newsworthy stories but for the daily assignments, the ability to cover the story often overrode news judgment. In other words, the editors made decisions based on such criteria as whether there was a reporter available, whether there was enough time to cover the story to meet set deadlines, and whether there was time available in the newscast.

Although news structures are usually developed with the appearance of a buffer between the journalist and the business side of the industry, there have been both blatant and subtle forms of crossing through that buffer zone. In a few cases, management has actually killed a story because it crossed the boundaries of corporate policy despite the fact that the story was newsworthy. Shoemaker and Reese (1991) wrote that it only takes a few such incidents to delineate the boundaries for the rest of the newsworkers. Since it is the goal of most journalists to get news on the air, they learn to function within organizational constraints. The most obvious control within the organization, as Shoemaker and Reese explained, is "straightforward and accomplished through a reward system. Promotions and salary raises go to the workers who perform their jobs well, 
while those who don't are demoted or fired" (p. 169). In his classic study of newsroom control, Breed (1955) discussed various reasons why journalists fall in line with the organizational expectations of the station. The journalist recognizes the authority of his superiors, and in many cases, understands that to succeed within the organization, he must follow the rules. Breed also discussed the comfort zone in which newsworkers must function. There is a desire to be a part of the group working toward a common goal in the newsroom. Finally, Breed noted that news has become a valued commodity. There is a constant need for new and fresh news. This is extremely important in radio news operations that struggle with the dilemma of recycling old news because nothing else is happening. Breed wrote that "instead of mobilizing their efforts to establish objectivity over policy as the criterion for performance, their energies are channeled into getting more news" (p. 331 ). Following the image of a factory model, journalists are expected to keep the assembly line moving at a consistent speed. Because journalists constantly struggle to fill the news hole, they become dependent on pseudo-news events.

\section{Pseudo-News Events}

Sigal (1973) noted that the use of press releases and news conferences has the greatest impact on news. As Sigal wrote: "The reporter cannot depend on legwork alone to satisfy his paper's insatiable demand for news" (p. 104). Boorstin (1971) echoed this opinion, writing that round-the-clock media required a never ending supply of news, and the most efficient way of securing that product is for someone to package it for news organizations as a pseudo event such as a news conference. As the speed of the assembly line moves onward, news people become more and more accepting of news releases and 
news conferences. In his work, Boorstin focused on the concept of pseudo events. explaining that this deadline pressure was the major reason journalists became so dependent on them: "Pressure toward the making of pseudo events became ever stronger. News-gathering turned into news-making" (p. 123). Boorstin identified four characteristics of a pseudo-event: a) It is not spontaneous; b) It is planted primarily for the purpose of being reported; c) Its relation to reality is ambiguous; and d) Usually it's intended to be a self-fulfilling prophecy (p. 120). The result of using pseudo-events, according to Boorstin, is a distortion of reality because "we are demanding more than the world can give us. We require that something be fabricated to make up for the world's deficiency" (p. 118$)$.

\section{Routines}

Our world today allows for the rapid dissemination of information, but for news organizations to process and manage this immense amount of information, they must establish a system of routine behaviors. News operations have developed ways to produce news in as orderly and manageable a fashion as possible. Routines are established to coordinate the news staff and run newsrooms efficiently. McManus (1994) wrote that present-day broadcast media are so driven by the market or economics of the business side of their operations that they lose track of the fundamental roles of journalists. McManus noted that "market logic is the mold for routines of discovering newsworthy events, selecting some of them for coverage, and pulling information together into a report. These routines constitute the daily expression of an organizational culture -- an accepted way of producing news in a particular media firm" (p. 85). Epstein (1973) challenged the 
idea that television news was a mirror on society: "Conceiving of television news in mimetic terms necessarily requires a certain blindness toward the role of the organization and organizational routines in the shaping of ncws reports and picturcs; a blindness which, from the point of view of the organization, may even be functional (p. 14). When organizational decisions restrict reporters' creativity and professionalism, they become cause for concern (Sigal, 1973). Despite the efforts of the individual, Sigal wrote that routines take on a life of their own. There is no doubt government officials and others learn these routines and how to take advantage of them. Shoemaker and Reese (1996) viewed these routines as constraints on the individual journalist. Expanding on Sigal's (1973) explanation for routines as a way to help with the operation of a news organization, Shoemaker and Reese (1991) discussed several factors. In broadcasting, journalist turnover is very high, necessitating operational processes to maintain order of news services. The technology of ever improving broadcast equipment requires procedures for specialized staffing and training. Finally, competition results in the use of news consultants who establish packaged formats which have proven successful. The problem with this routinized approach, according to Shoemaker and Reese, is that "the factory environment does not encourage such professional values espoused by newsworkers who are evaluated on their productivity--doing assignments on time, rather than necessarily well, as epitomized by the 'quick and dirty' story" (p. 108). Fallows (1996) also found these routines to be a root cause for the industry's hesitancy to review the quality of its work: "The conventions of choosing 'the news' are so familiar, and so much of the process happens by learned and ingrained habits, that it is easy for journalists 
to forget that the result reflects decisions, rather than some kind of neutral scientific truth" (p. 260).

Professionalism has been targeted by Soluski (1989) as an efficient and economical way to control the behavior of journalists. Soloski noted that, if journalism is regarded as a profession, there are specific rules and norms that all members practicing journalism must follow. These norms or conventions would include objectivity and accuracy. Reporters develop routines that help them live up to these norms or expectations. One such routine highlighted by Soloski is the tendency to use official sources when getting reaction on stories. Because news sources are drawn from the existing power structure, news tends to support the status quo (p. 215). Furthermore, Soloski wrote, the routine of news beats is influenced by news organizations and, in an effort to maximize the return on staff and equipment, beats are established: "The choice of beats results from the interplay of news professionalism and the resources of the news organization" (p. 215). Beyond the control of professionalism, each news outlet sets in place its own news policies. These intra-organization controls further limit the freedom of reporters. Such policies could involve theme orientation of the operation (i.e. a family station), the chain of command, the format and presentation of news, reprimands, and rewards. Using organizational theory, then, Soloski wrote that "news professionalism biases news at a societal level" (p.225). The individual news organizations' policies would tend to bias news even further, but Soloski noted that, as long as the individual news policies do not go against their professional norms, most reporters will not feel a constraint on their ability to present information accurately to the public. It is clear, however, that such policies do limit the 
type of stories to be presented.

Drew (1972) tied role expectations of reporters with their behavioral patterns and cxamined the relationship between role expectation and role performance. When the reporter's view of what his or her role should be doesn't mesh with the expectations of management, conflict arises. Drew wrote that such conflict either forces the reporter to leave the news operation, essentially walking off the assembly line, or become more passive, resulting in the failure to meet traditional journalistic goals. The expectations of the news organization, Drew noted, appeared to be a potent force in the decision-making process of reporters. This follows role theory in that the expectations of those who can reward or punish an employee are of greatest importance. Other factors that affected the behavior of journalists in Drew's study included the audience, expectations of fellow reporters, and their own professional ideals.

\section{Deadlines}

Whitney referred to deadline pressure as "breathless journalism" (1971, p. 154). In his work on objectivity, Whitney (197l) wrote that the indiscriminate application of speed, no matter how complex the issue, threatens objectivity and ultimately distorts the true picture of the event. Epstein (1973) wrote that "since the wire services provide only a minimal amount of information about the context of an event, and since the decisions concerning which stories are to be assigned coverage are made under time pressure, assignment editors must rely to some extent on relatively stable criteria, routines, and operating rules for quickly dispatching correspondents and camera crews (p. 143). Beyond the idea of distortion is the concern of manipulation. Because a single news 
source has an established record with reporters, he or she is able to release information that will be transmitted just because they said it (Sigal, 1973). The routine of going with the straight ncws approach to avoid accusations of subjectivity also results, according to Sigal, in giving access to powerful officials to set the agenda by simply calling a news conference.

\section{Presentation}

In broadcast news, the format or presentation plays a larger role than in the print media. In many areas the broadcaster has more control and fewer organizational constraints. Shoemaker and Reese (1996) cited various studies showing that broadcast reporters usually don't have regular beats and have fewer editors (Becker, 1982). However, because of the presentation aspects of TV news, their work is just one small part of a whole creative package and therefore doesn't stand on its own.

The final result, Griffin ( 1992) wrote, is exciting, brief, and complete news narratives from bits and pieces of sound and video that produce a blurred picture of reality. In his study on TV news presentation, Griffin focused on what he termed "symbolic visual syntagms (a semiotic term referring to the sequential or syntactical ordering of meaningful units)" (p. 132). Griffin found that stories were developed through syntactic combinations of visual symbols or image bites. The key, according to Griffin, to this observation is that these image bites contribute to the validity of the narrative and "legitimized the authority of the reporters and anchors as arbiters of the facts" (p. 133). Berkowitz (1990) found that the format of a broadcast station actually plays a role in determining what stories are aired: "Interviews with journalists found that they chose 
among the three story types according to quotas in the format" (Berkowitz, p. 63). These three areas were issues, spot news, and entertainment. With such limitations, the ability to provide a truly diverse newscast is inhibited.

Briefly touching on radio as a unique broadcast medium, Adelsberger (1993) defended the succinct writing and quick format. The key to quality for any journalistic medium is in the content. Adelsberger wrote that "the strength or weakness of one medium over another should not be measured by how much space they have to fill, but by how they fill it" (p. 41). The radio reporter must get to the heart of the story quickly and clearly. To delay results in a lost or bored audience. National Public Radio has proven that a more in-depth style of reporting is competitive; however, most radio stations allow themselves to be limited in the types of stories they cover by the constraints of the technology (Adelsberger, 1993). Radio executives are finding themselves pushed by economic constraints. Viles (1993) wrote that networks and broadcast services are being pushed to provide more flexibility in the types of programming provided. Some of these same services play a role in how news operations decide on staffing and the ultimate affect on the quality of the content. These organizational decisions may be placing constraints on journalists, affecting their professionalism in the decision-making process, and ultimately affecting the quality of the content in their newscasts.

$$
\text { Individual Influences }
$$

\section{Media Agenda Setting}

It is obvious the media can not broadcast all of the news of the day. There simply isn't enough time within the newscast, and even if time were not a factor, it is unlikely an 
audience could be maintained unless the news was packaged in some fashion to hold the interest of listeners. Picking and choosing the news has traditionally been seen as the role of the gatckecper as well as a line of editors (White, 1950). However, Whitney and Becker (1982) indicated that the editors at the various newspapers and broadcast stations really don't dictate as much of the news agenda as the national wire services and the networks.

Agenda setting research has been extended from audience perceptions of agendas to media agenda setting. A key question in future research into agenda setting, according to McCombs and Shaw (1993), is to determine who is setting the agenda. Fallows (1996) wrote that politicians are trying to set the agenda, and the media is trying to battle against this manipulation. However, the routines developed within the journalistic arena inhibit reporters from doing much to prevent being used. For example, not enough time is available to really dig deeper into stories, and reporters are forced to get a quick voice cut from a regular newsmaker and write around it. Fallows noted that this has led to a hostility developing between political leaders and those in the media: "Public officials become more manipulative and cunning to try to get their message past the hostile press -and the press becomes even more determined to point out how insincere the politicians are (p. 63). Recognizing, then, the significance of the role media play in setting the news agenda, newsworkers have been asked what they consider to be the most important criteria for newsworthiness. Sigal wrote that, despite their many definitions of what news is. "the newsmen's criteria fail a crucial test: they do not describe what their proponents do in practice" (1973, p. 1). Epstein (1973) wrote that "the fact, then, that newsmen have 
certain shared values about what constitutes "news" does not necessarily mean that these news values prevail when they run counter to the structural constraints and logic of the organization (p. 37). Newsworkers have always complained about the quality of the product they present. As the keynote speaker at the 1993 Radio and Television News Director's Association, CBS Anchor Dan Rather recognized the Hollywoodization of the craft. Rather is quoted in the October, 1993 Broadcasting and Cable as saying: "We can say, No more.' We can fight the fear that leads to 'showbizification'." Although Rather expressed a great deal of frustration with the current state of the news industry, he said he had not given up hope.

In addition to the choice of whether to cover the story is how to cover it. Some of these same organizational routines come into play. News reporters often feel safe by contacting the same newsmakers for comment on related issues. Sigal referred to this as a herd instinct "to follow a few bellwethers who have not led them astray in the past. The bellwethers are opinion leaders in the community" (1973, p. 40). These same people are often seen by management as the key demographics because of their buying power. Traditionally, the key audience for news radio has been professionals, usually men, in the 35 to 54 age bracket. People who fall into this category usually have discretionary income to spend and are viewed as a prime target by advertisers. Therefore, pressure if ever so subtle, is placed on the reporters to continue calling on these professional people for comment and reaction to stories. This routine also allows the media to be used to legitimize the status quo and acts to cut off outside views. In fact, Sigal found that, if a potential story did not fall nicely within the standardized definition for news, many 
reporters chose not to cover the event. These definitions are part of the value system of journalists known as conventions. Sigal wrote that "information that radically violates these conventions will be subject to greater scrutiny on the desks than information which does not, and reporters may find it harder to justify its newsworthiness" (p. 66). The result then is safe news that tends to focus on conflict of a simplistic nature with a push for the sensational or dramatic. Powers (1977) called the result idea pollution. Fallows (1996) criticized the national press for always looking for the hottest scandal rather than trying to put events into perspective. Such perspective requires journalists take more time for story research and writing. Reporters complain about not having enough time, but Fallows wrote that they are all too busy looking for what is urgent, and they miss the daily chore of telling us what is important and why (p. 134). Journalists are too busy catching the hottest item on the assembly line to gauge an accurate picture of the day.

\section{Definitions of News}

The institution sets the tone for the stories that get major coverage based on economic factors. Nord (1980) found that the greater the market power of a producer, the more standardized will be the formula. At the organizational level, producers and editors maintain considerable control over the selection of content while balancing the constraints of staying within the budget and following the format of the station. The individual reporters sometimes fight to maintain some creative power in this process, but this requires that they step away from the assembly line. Professional journalists are responsible for the decisions made in the field on the importance of an event. Ettema and Whitney (1987) wrote that, to retain control of their markets, firms avoid the risks of 
innovation. Each reporter approaches a story differently and processes what is happening according to that reporter's personal life history. Many researchers have noted the subjectivity of knowledge and the conflict over what is truth. Sigal found that newsworkers fell into a kind of trap of interpretation "not unlike that of a historian or social scientist seeking to establish the validity of his interpretation of events" (1973, p. 2).

Sigal wrote that most news depends on choices rather than decisions. A variety of things affect those choices, including competition. Within the organizational structure, reporters follow competitive behaviors such as monitoring other media and listening to police scanners. Pushed by demands to have every story the competition has, reporters develop the routine to cover all stories from these sources. There are rarely thoughtful discussions prior to deciding whether to cover a story. Rather, in a kind of herd mentality, journalists race to cover what the competition is following (Sigal, 1973). In a specific study of gatekeeping and local television news, Berkowitz (1990) did find some patterns in the stories chosen for the newscast. Those stories that related to government/politics, accidents/disasters, and crime were more often aired. Berkowitz also found that timeliness, which ties in directly with breaking or spot news, had the strongest likelihood of being chosen for broadcast. Fallows (1996) noted that one of journalism's fundamental roles is to put the events of the day into context. However, taking the time to develop the historical context of a story goes against the broadcast industry's need to highlight the present. The journalist believes that management expects reporters to work within the factory format. Many of the news stories that receive extensive coverage involve complex issues such as billion-dollar deficits, massive starvation around the world, the rise and fall 
of democracy, etc. Fallows wrote that by choosing to cover only the superficial top layer of such complex stories, reporters send a message to society that its members have no connection and, therefore, no controi over their world. The goal, according to Fallows, should be to present a whole picture so that people can see the connections between causes and consequences.

Another factor used to decide newsworthiness is proximity since listeners want to know what is happening in their local areas. Competition is an issue in this area as well. McManus (1992) wrote about the conflict in meeting the desire of the audience for local news and the desire for larger profits for the organization by expanding the audience size. McManus acknowledged the difficulty of broadcast organizations in that "newspapers can zone editions to reduce this problem and readers can skip stories that do not pique their interest, but television and radio are likely to lose customers if they dwell too long on what is important in just a part of the market" (p. 799). The result, according to McManus, is a newscast filled with human interest stories and pieces that arouse emotional response.

One gauge used to assess quality in news broadcasting is whether the programming is meeting the needs of the audience. McCarthy (1985) wrote that the media has fallen so short of expectations that the question of trustworthiness comes into play as well as the credibility of the individual news reporter. In her survey, McCarthy wrote that "people complain that the press is cynical, that it does not stress American values, that it does not give us any good news about ourselves" (p. 394). In more recent years, the impact of CNN on the style of news reporting in the broadcast industry has been powerful. The local stations and national networks seem to be making a comeback to 
traditional news as market share grows for this style of hard news coverage (Eisenberg, 1990). The 1989 Loma Prieta earthquake forced Bay Area stations to deliver solid news and one viewer, Ingrid Heiseil, was quoted by Eisenberg as saying: "Despite the tragic circumstances, it was a welcome change from some of the average fluff of daily news" (p. 67).

Once a story has been identified as being newsworthy, the reporter has the difficult task of covering all sides of the issue. More than in the print media, broadcasters are constantly looking for the sound bites or visuals that will be used as a backdrop for the story. Altheide (1987) found that assignment editors routinely make judgments on whether a story is worth covering based on the opportunity for good sound/visuals. When the time comes to determine where to place a story in the newscast, producers are also looking for the most dramatic piece, often based on sound or visuals. Griffin (1992) saw a reverse relationship in the decision-making process concerning visuals. Griffin maintained that the stories were chosen based on the importance of the issues and topics, and then visuals or sound were sought to enhance the story. This indicates that the stories shape the visuals rather than the visuals determining what stories get coverage. Griffin wrote that the distinctions between news and infotainment are difficult to identify, and that "external events may be little more than grist for the mill of news programming, and the formats of news presentation may not enjoy any particular information privilege over fictional formats which draw from world events" (p. 124). Using organizational routines to determine what is newsworthy often results in decisions that disrupt the journalist's goal of objectivity (McDonald, 1978) 


\section{Event Coverage: Objectivity}

As McDonald wrote: "The most pernicious journalistic convention is the notion that a thing is not newsworthy until it becomes an event; that is, until something happens" (p. 149). If the story doesn't fall on the conveyer belt, the journalist doesn't consider it. This results in stories either being reported out of context or not reported at all. This may be the cause for the common complaint that news is focused on conflict and simplistic issues. McDonald blamed this on the journalistic convention that a story must hold the readers' interest to qualify as a story worth covering. This demonstrates the economic pressure placed on the journalist from the institutional and organizational levels rather than a push for objective news reporting. Fallows (1996) noted that editors have become more like managers, and journalists are looking for more ways to ensure their positions: "In these circumstances, even the most dedicated and principled realize they must look out mainly for themselves, since no one else is watching out for them" (p. 72). Journalists struggle with the realities of working within the constraints of the organizational structure and the desire to meet their personal journalistic goals, which for some may follow the 1947 Commission on Freedom of the Press call for journalists to provide society with "a truthful, comprehensive, and intelligent account of the day's events in a context which gives them meaning" (p. 21).

Most journalists strive to provide truthful, comprehensive, and intelligent accounts of the day's events, but they can't help but be affected by their personal histories and experiences that affect how they view events (McDonald, 1978). Journalists also tend to routinely categorize stories and events based on what they have covered and reported on 
in the past (Stockings \& Gross, 1989). This biasing influence, according to Stocking and Gross, can be seen when stories are ambiguous and journalists question in what frame to place the crent. Decision makers on the assembly lines, such as assignments editors and news editors, have separate files for common categories of news. These categories include crime, politics, features, etc. The goals of the organization may also affect the light in which certain stories are presented. To maintain a large and supportive audience. Stockings and Gross examined the tendency of reporters to present good stories about the major emphasis of the media in question.

Following the organizational routines approach, journalists are taught how to lay out straight news with minimal interpretation (Sigal, 1973). However, these conventions restrict the journalist's search for context of complex stories. As Sigal noted, "journalists found themselves under attack for concentrating on spot news at the expense of underlying trends in society" (p. 68). Tuchman (1978) wrote that journalists "make more work for themselves by choosing to cover several stories in a cursory manner rather than covering one story intensively" (p. 124).

The public will often pinpoint a specific journalist and charge him or her with having a bias in the manner in which he or she covers news events. However, Epstein (1975) discussed a far more pervasive form of organizational bias that underlies the network news industry, if not the local organizations as well. Epstein wrote that "all three networks act to filter out correspondents who have a high degree of personal commitment on issues, or appear to the audience to have a 'bias,' and advance correspondents who hold or adopt a style of presenting the news that fits the network's requisites" (p. 201). Epstein 
further examined the themes developed by producers and the resulting categorization of news to fit within those themes. Epstein made it clear he felt the requisites of the organization were far more to blame for distorting the news than personal biases. McManus (1991) also found that organizations and corporate self-interest strongly influenced news content and resulted in a high percentage of violations of objective reporting. McManus viewed four areas: a) personal bias of reporters, b) self-interest of news organizations, c) self-interest of social elites, and d) human error. Failure to attain objective standards leads to the distortion of truth.

Objectivity and truth go hand in hand. According to the goals of the 1947 Freedom of the Press Commission, journalists should be striving to present the truth in a context that gives it meaning. Epstein (1975) wrote the problem is that the journalist is not in a position to establish truth because he is dependent on self-interested sources for their versions of reality. This is especially true if reporters have fallen into the routine of calls to established sources within government for the major or, in some cases, only reaction to stories. Lippman (1922) made a poignant distinction between news and truth saying: "The function of news is to signalize an event; the function of truth is to bring to light the hidden facts, to set them into relation with each other, and make a picture of reality on which men can act." Epstein (1975) recognized that most journalists would find it difficult to accept this distinction between news and truth; however, Epstein outlined various organizational constraints that limit the power of even the best journalist. These include deadlines. space availability, and budget limitations.

Because journalists must rely on official sources for much of their technical 
information, they do not have the ability within the organizational structure to check their facts (Epstein, 1975). They can not, in essence, step off the line to do further research because of such organizational constraints as deadlines. It is this use of official versions and comments that results in accusations that journalists maintain the status quo. Sigal (1973) discussed how the journalist's view of the truth is affected. Official sources have their own agendas and will shape their responses to reporters' questions to maintain their goals. In his work on the social forces that control the newsroom, Breed (1955) noted that the bulk of the news is reported objectively, but that policy news may be slanted or buried so that important information is denied the public.

The cognitive process used by journalists was studied by Stocking and Gross (1989) who looked at how journalists determine truth. At issue was whether the preconceived ideas of the journalist affected their ability to objectively review diverse aspects of a story. Stocking and Gross found that, "when choosing between incoming information that is consistent with their theories and incoming information that is inconsistent, people tend to regard the supportive information as more valid" (p. 10). In reviewing any information pertinent to a story, the journalist goes through a process of trying to balance the various sides. Barrett (1982) discussed the common perception that there are two sides to any issue. He maintained there is a third side which is that dimension which converts a simple controversy to a solid, complicated, and convincing reality.

Barrett wrote that a goal of exchanging doubt and suspicion for accuracy and honesty would resolve the problem of credibility. However, the institutional constraints 
on the radio journalist fight against this as demonstrated by the trend toward more technological services and fewer reporters. Because of economic pressure, station owners are chousing to link directiy into governmental services. These stations simply record the city/county governmental meetings and take a quick sound bite to plug into a story provided by the city's public relations officer (Connors, 1991). Connors provided many examples of distortion because the reporters are not on site. In one instance, the reporter listening back to the tape had no idea whether Republicans and Democrats in the U. S. Senate Chamber were applauding or just the Democrats. There is no opportunity in this situation to note the reactions of people in the audience, or more importantly, to actually interview those expressing a different point of view from the establishment. Connors agreed with others who believe radio still has the potential to be a serious contender in the news arena: "Radio, within the news industry, is very often considered a bastard child, a not very serious news-gathering medium. It is serious. And radio needs to take itself more seriously" (p. 42).

McManus (1994) called on journalists to follow through on their duty to be as objective and accurate as possible by checking out the facts they report and applying some reality standards. He noted that often today's journalists are abdicating their roles as watchdogs of government and relying on passive means of discovering information, such as press releases and news conferences: "Passive discovery tends to surrender control over the public information stream to powerful interests in government, large corporations, and among the wealthy" (p. 107). It's as if those in power are allowed to provide the material that comes along the assembly line as journalists stand ready to report it. 


\section{Theoretical Framework}

The foundation for this study was based on some of the classic work involving mass communications research. Tuchman (1978) devcloped a clcarcr picture of how news people and news organizations set up certain routines to cope with the business of presenting unexpected events. The research by Epstein (1975) and Sigal (1973) was used to lay the groundwork for the study of the quality of news content. Both Epstein and Sigal wrote extensively about many constraints affecting the quality of the news product. For a more current picture, Soloski (1989) was used to detail how organizations use the concept of professionalism to control news people, and Fallows (1996) was used to point out how the individual journalist falls into the traps of organizational and institutional constraints. The work of Shoemaker and Reese (1996) involving the result of the routines set up by organizations and journalists was integrated into this research The gatekeeping concept was outlined beginning with White's (1950) study, followed by the update of White's work by Snider (1967). Moving to the broadcast industry, Bailey and Lichty (1972) was used to demonstrate the various gatekeepers involved in the development of a television story. The study of television news by Drew (1972) detailed how the role expectations of reporters affected their work. Berkowitz (1991) and McManus (1992) both studied television news and the how the quality of the product is affected by the constraints placed upon reporters. Finally, Bantz, McCorkle, and Baade (1980) developed the news factory model that is the framework for this study. Bantz et al. focused on television news, whereas, this study focused on all-news radio. 


\section{CHAPTER III}

\section{METHOD}

The field research was conducted in two separate participant-observations periods. The first lasted one week (April $10-14,1995$ ) at KMPH Radio in Fresno, CA. The second was a three-week field study (June 26, 1995 through July 14, 1995) at KCBS Radio in San Francisco. The research took an interpretive approach and presented the picture of both stations in context. By using the participant-observation method, the researcher was immersed in the newsroom environment. Personal precautions were taken to avoid a complete member role; it was necessary to stay remote enough to recognize all significant events or non-events that should have been noted. Following the participant observation criteria of the Chicago School of Sociology, the researcher was studying people in their natural surroundings, studying people by directly interacting with them. gaining an understanding of the social world, and making theoretical statements about the member's perspective.

Some preliminary questions were asked prior to the observation period in an attempt to determine the financial background of these stations. Interviews were held with the stations' news directors several weeks prior to the case study to find out the resources made available to the newsrooms. Follow-up interview sessions were built into the case study. The atmosphere was professional yet casual. Questions were usually open-ended and the researcher tape recorded each session. During the first third of the study, the researcher concentrated on descriptive questions that would verify what was being noted. Toward the middle of the project, the questions moved into a more 
structural style that involved the beginnings of data analysis and the formations of tentative categories and themes. Finally, in the last third of the field study, the researcher focused on contrast questions that would builu and verify the categories developed fiom the data analysis. Along with questions about station resources, general managers were asked about the requirements of the network affiliation, the commercial side of the station, and their expectations of news content. Regular interviews were conducted with other station personnel at different hierarchical levels. All interviews were personal interviews conducted at the radio stations. All formal interviews were tape recorded although there were informal questions asked of various news personnel throughout the observation periods. The list of personnel recorded in formal interviews is as follows:

At KCBS, One Embarcadero Center, Suite 3200, San Francisco, CA 94111:

General Manager Frank Oxarart, (July 12, 1995)

News Director Ed Cavenero, (June 22 and July 13, 1995)

Managing Editor Todd Smoot, (June 29, 1995)

Assignment Editor Dory Culver, (July 6, 1995)

Editor Terry Conway, (June 28, 1995)

Editor Paul Halsey, (June 20, 1995)

Reporter Mike Sugerman, (July 7, 1995)

Reporter Jerry Wilcox, (July 10, 1995)

Anchor Mike Pulsipher, (July II, 1995)

Anchor Jan Black, (July I I, 1995)

Anchor Lois Malconian, (June 27, 1995) 


\section{At KMPH, 5087 E. McKinley, Fresno, CA 93727:}

General Manager James Rowtan, (April 14, 1995)

News Director Angela Ehigiator, (April 10 and 13, 1995)

Assignment Editor Scott Miller, (April 12, 1995)

Consultant Karen Humphrey, (April 13, 1995)

Editor Stephanie Terronez, (April 12, 1995)

This research involved a set of interviews with the people making the decisions on news content. These interviews lasted from 30 minutes to an hour and took place soon after the actual newscasts to ensure that personnel would remember what caused them to decide on running specific stories. The questions focused on the process by which stories were chosen. At issue was whether traditional news values such as significance, proximity, timeliness, conflict, and known principals were the driving forces behind those decisions or whether organizational routines had a more substantial role. Questions were designed to determine if those involved in putting together the newscast looked for the important stories of the day and how to present them truthfully or whether they were following the factory model and allowing organizational routines to guide them. Editors and the general manager were asked about the importance of diversity and how diversity was addressed in the policy of news coverage. Finally, questions were formulated that determined whether the decision makers in the newsroom felt any concern about organizational constraints affecting the decision-making process and ultimately the content of the newscast.

The researcher observed during the day shift from Monday through Friday. It was 
important to observe routines as well as special and unanticipated coverage since time was spent observing the work in the newsroom as well as the journalistic work in the field.

The key io qualitative research lies in the field notes taken by a disciplincd and knowledgeable researcher. During the first week, field notes included information about the atmosphere of the newsroom, its physical characteristics, what people did, and social communication. Special care was taken to note what was said, how it was said, and what was implied. Prior to conducting interviews, management assured the researcher and the staff that there would be no retaliation for comments made. Although that assurance was sincere, there were times when the researcher chose to keep the name of the interviewee anonymous to protect his or her confidentiality. Because of the nature of journalism, it did not seem unusual for the researcher to be taking notes and tape recording events. Special notations and color coding was used to keep track of the various types of field notes, direct observation, analytic and personal notes. These handwritten notes were then entered into a computer for ease in organization and retrieval later in the interpretation process. Informal social maps were also drawn early in the project to display the physical relationships of the various levels of management within the station.

During the first two days of observation. the researcher noted how assignments were made at the beginning of each day as the editors and others decided the news content to be covered. Special note was given to outside constraints that affected the stories chosen for coverage and whether the news director was involved in the daily decision making. It was also noted if reporters had any input into story assignments and if particular reporters were targeted for specific types of stories. Throughout the rest of the 
three-week observation period, it was noted how story assignments were adjusted to meet the events of the day and any outside constraints placed on the newsroom personnel.

Organizational, individual, and institutional constraints such as cconomic limitations, bias, and competition have resulted in reporters developing routines to meet the requirements of the job. Those routines, however, often have a net effect of reducing news content diversity and quality. To link these constraints to the quality of coverage, three separate hours of continuous news coverage were taped from the morning, mid-day, and afternoon drive news blocks at both stations. The length of time between repetition of lead stories was noted as well as the type of story being aired. The network news broadcast at the top of the hour was not included in the coding because this study focused on the local news production rather than what was developed at the national level. A qualitative content analysis was done to note the diversity of coverage. At KCBS the midday block was taped on the 4th day of observation, June 29, 1995. The afternoon drive block was taped on the $11^{\text {th }}$ day of observation, July 10,1995. The morning drive block was taped on the 15 th day of observation, July 14. 1995. At KMPH the mid-day block was taped on the Ist day of observation, April 10, 1995. The morning block was taped on the 3rd day of observation, April 12, 1995. The afternoon block was taped on the 5th day of observation, April 14, 1995. An analysis of the content within these taped segments has augmented observational notes in answering the research question of whether organizational constraints have a detrimental effect on journalists trying to provide a true picture of the day's events. This analysis was also used to formulate questions for news personnel. 
The following is a list of the categories used to divide the stories aired:

1. Hard news such as economics, health and safety, and politics.

2. Feature stories such as a new way to track the location of $91 !$ calls from cellular phones.

3. Emphasis on political news because newsmakers are considered reliable. An example of this could be the reaction of the mayor to block grant funding from the federal government.

4. Pseudo-news events such as stories developed at news conferences or through news releases.

5. Spot news, crime, or disaster coverage such as a plane crash, fire, or earthquake.

6. Use of follow-up or advance stories to fill the news hour and for competitive purposes. These are preview stories of an event that will be covered in the near future or a follow-up story of an event covered in the recent past. This may include stories about a trial set to begin or the visit of the U. S. President.

7. Use of regular newsmakers other than politicians such as an attorney for legal analysis.

8. Regularly scheduled governmental meetings such as city council or county supervisors.

Reliability and Validity

Other professional journalists were also asked to review the study and questions to provide feedback before the actual case study began. These same professionals were used 
throughout the research project as informants to help verify the external consistency of data collection and analysis. Internal consistency was verified by regular observations in similar situations to detcrmine if behavior was repeated and routine. It was possible to develop informants inside each station to help with internal consistency.

Various measures were taken to ensure validity. Ecological validity was attained through the previous journalistic experience of the researcher, plus the brief introductory period before the field study began. The project was done within the natural environment of each radio station, and this researcher's report has been made available for review. The members of each station have access to the final report as well as a chance to review potential themes and categories outlined by the researcher during the field study. This will provide validation by those involved in the study. The researcher's prior experience in broadcast journalism ensured competent understanding of the internal workings of a radio newsroom.

Daily notes were reviewed as part of the conceptualization of the data. Themes, concepts, and categories emerged during this process and were entered onto a computer for continued analysis. This was an open coding period. Once a week during the actual field study, axial coding was performed as a second pass was made through the data. During axial coding, the ideas and themes that emerged during the open coding period were organized for future analysis. The researcher was looking for consequences, conditions, interactions, strategies, and processes. This axial coding continued immediately following the field study. As more evidence was added to support emerging themes, the selective coding process began. By scanning the data collected, various 
examples of core themes were selected to be used for verification. It was at this point that major themes were developed and guided the interpretation of the data.

Once patterns were identified that supported major themes, the researcher used the illustrative method to apply theory. Examples from the field study were used to demonstrate how the theory can be applied. Because a second radio news operation was observed, analytic comparison could be used to reveal the differences and similarities between major market and medium market stations involving identical situations. 


\section{CHAPTER IV}

\section{RESULTS}

One's visual image of the beginning of a shift in a factory calls to mind dozens of people leaving the assembly lines as dozens more come through the gates to take their places. Their morale is displayed by their monotone voices and dull facial expressions. The work is boring and few care whether they make company quotas let alone how they could improve the quality design of the work. These workers, who believe management views them as cogs in the wheel, follow the routines of their profession with little creativity or initiative.

This visual picture can be transferred to many of the professional journalists observed in this study. A few journalists take the initiative to step outside the normal routines of the day, but most fall in step with the same routine as the day before. The day begins with the arrival of reporters and anchors. At both stations these journalists arrive at various times for their shifts, and the senior management staff arrive between 7 a.m. and 8 a.m. At both KCBS and KMPH, the assignment editors begin by combing through the future files and newspapers. Some story ideas are also developed from breaking news the night before. The editors making the decisions on news stories to be covered use their normal sources for ideas while most reporters wait for their assignments. Except for those reporters who actively engage in the decision-making process, the distribution process is a one-sided communication in which the editor tells the reporter what stories to cover. There was clearly more reporter participation noted at KCBS than at KMPH. 
KCBS reporters sometimes had suggestions to follow up on stories they had covered the previous day. Bureau reporters sometimes had ideas developed through mail or phone calls directly into the bureau office. On a few occasions, KCBS reporters had unique story ideas that they presented to the assignment editor, but during the observation period, only about one-half of these were assigned. The KCBS assignment editor handles each reporter individually. She discusses story ideas with the reporters and gets their feedback. This organizational routine proves to be very productive in making it clear what the expectations are for the story angles. These one-on-one meetings continue throughout the day as reporters call for updates or changes. At the individual level, reporters have a positive response to this style of handing out assignments and, according to the assignment editor, they do a better job of covering their stories. The news director meets with the assignment editor and the managing editor at least once a day for an update on assignments and news coverage

At KMPH, the assignment editor for radio also doubles as the assignment editor for the television side. Because this editor is responsible for two sets of reporters, there is little time for one-on-one discussion about the quality of the stories or the unique angles to be considered. Assignments are made to each reporter via the computers, and the personal interchange, which results in mutual respect at KCBS, is not apparent at KMPH. This organizational constraint requires the KMPH assignment editor to coordinate coverage of certain events by getting a reporter and a photographer together at the same time. Television reporters are asked to feed stories for radio, and radio reporters are sometimes used to handle a story for the television side. This cooperative effort is not 
popular with the staff and becomes an individual constraint affecting the quality of the news product. In an effort to encourage staff input and creativity in the story selection process, the news director at KMPH holds a $10 \mathrm{am}$. staff meeting to discuss story assignments and additional ideas. These meetings last about one-half hour. A second news meeting is held at 2 p.m. to review for the afternoon and update changes in the assignments. Although story ideas are kicked around, few assignments are made following these meetings.

Even with the input of a staff of news professionals and the ability to broadcast news 24 hours a day, all-news stations limit the type of stories that air. KCBS is no exception. A content analysis has been included as part of this research to review the level of diversity noted during the observation period. Three separate hours of news were recorded at both KMPH in Fresno and KCBS in San Francisco. These recordings included a one-hour news block from the morning drive period, mid-day drive period, and afternoon drive period. Each story developed or rewritten by the staffs of KCBS and KMPH was then coded. The stories were tabulated as shown in Figures 1-6, one bar graph for each time period. In a few cases, a story was counted in two categories. For example, the story may be an advance story dealing with a hard news topic. The categories used for coding were:

1. Hard news such as economics, health and safety, and politics.

2. Feature stories such as a new way to track the location of 911 calls from cellular phones.

3. Emphasis on political news because newsmakers are considered reliable. An 
example of this could be the reaction of the mayor to block grant funding from the federal government.

4. Pseudo-news cvents such as storics devcloped at ncws conferences or through news releases.

5. Spot news, crime, or disaster coverage such as a plane crash, fire, or earthquake.

6. Use of follow-up or advance stories to fill the news hour and for competitive purposes. These are preview stories of an event that will be covered in the near future or a follow-up story of an event covered in the recent past. This may include stories about a trial set to begin or the visit of the U. S. President.

7. Use of regular newsmakers other than politicians such as an attorney for legal analysis.

8. Regularly scheduled governmental meetings such as city council or county supervisors.

In Figures 1-6, the percentage of stories that fall in one of the above categories was calculated based on the total number of stories in each news hour. In Figure 1 , there were 24 news stories developed by the KCBS news department. Five stories were included in two categories because they were advance or follow-up stories involving hard news subjects. In Figure 2, there were 17 news stories with three stories falling into two categories because they were both hard news and advance or follow-up stories. In Figure 3, there were 17 news stories with four stories falling into both the hard news and advance or follow-up categories. In Figure 4, there were 28 news stories with six stories falling 
into both political news and pseudo-news events. In Figure 5, there were 26 news stories with eight stories falling into the hard news category as well as spot news. There were also four stories that fell into both the political news category and pseudo-news events. in Figure 6, there were 18 stories with eight stories falling into both the hard news and spot news categories. 
Figure 1

KCBS Morning Drive Time 7 a.m. - 8 a.m. on July 10, 1995

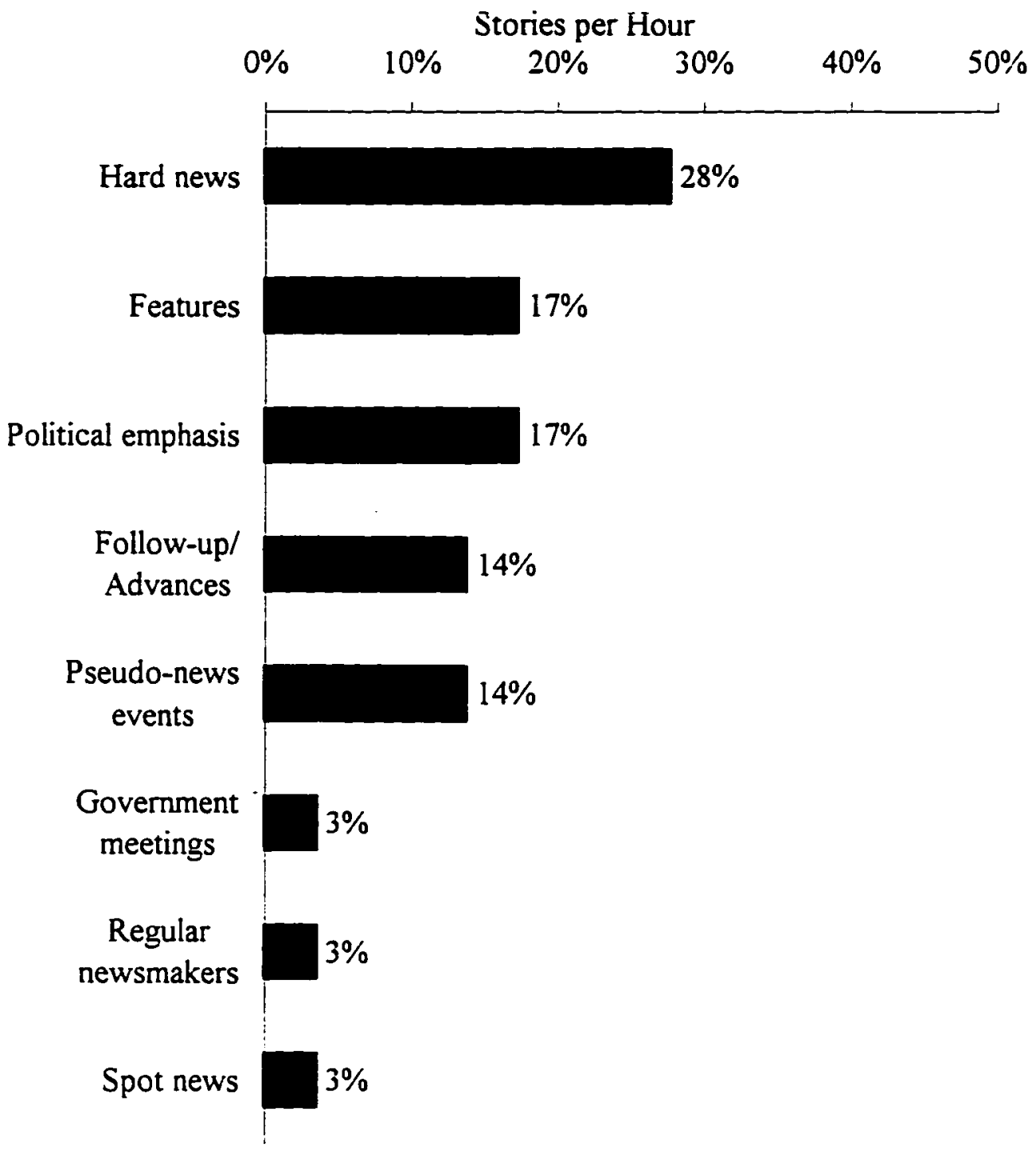


Figure 2

KCBS Noon Drive Time 12 p.m. - I p.m. on June 29, 1995

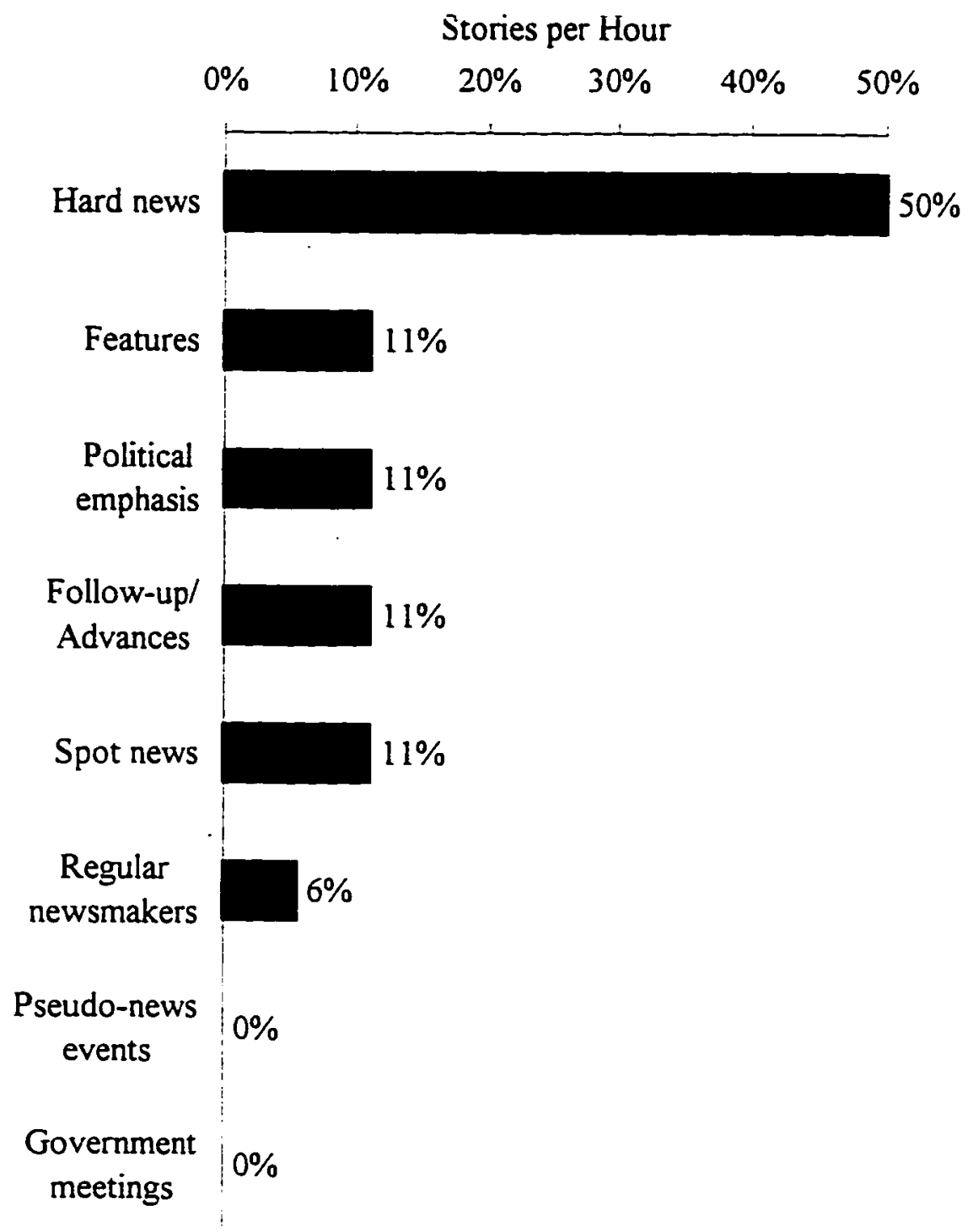


Figure 3

KCBS Afternoon Drive 5 p.m. - 6 p.m. on July 10, 1995

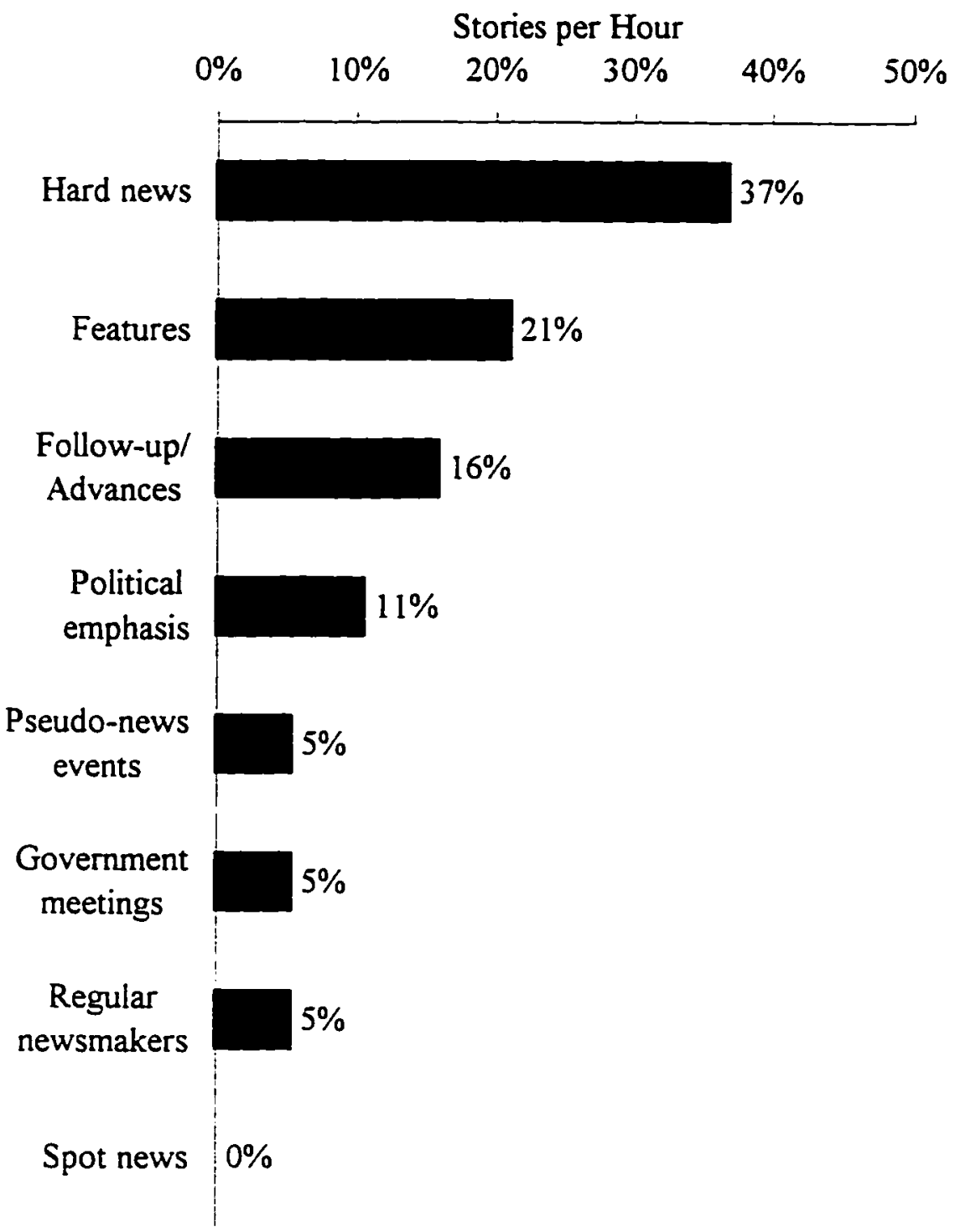


Figure 4

KMPH Morning Drive Time 7 a.m. - 8 a.m. on April 12, 1995

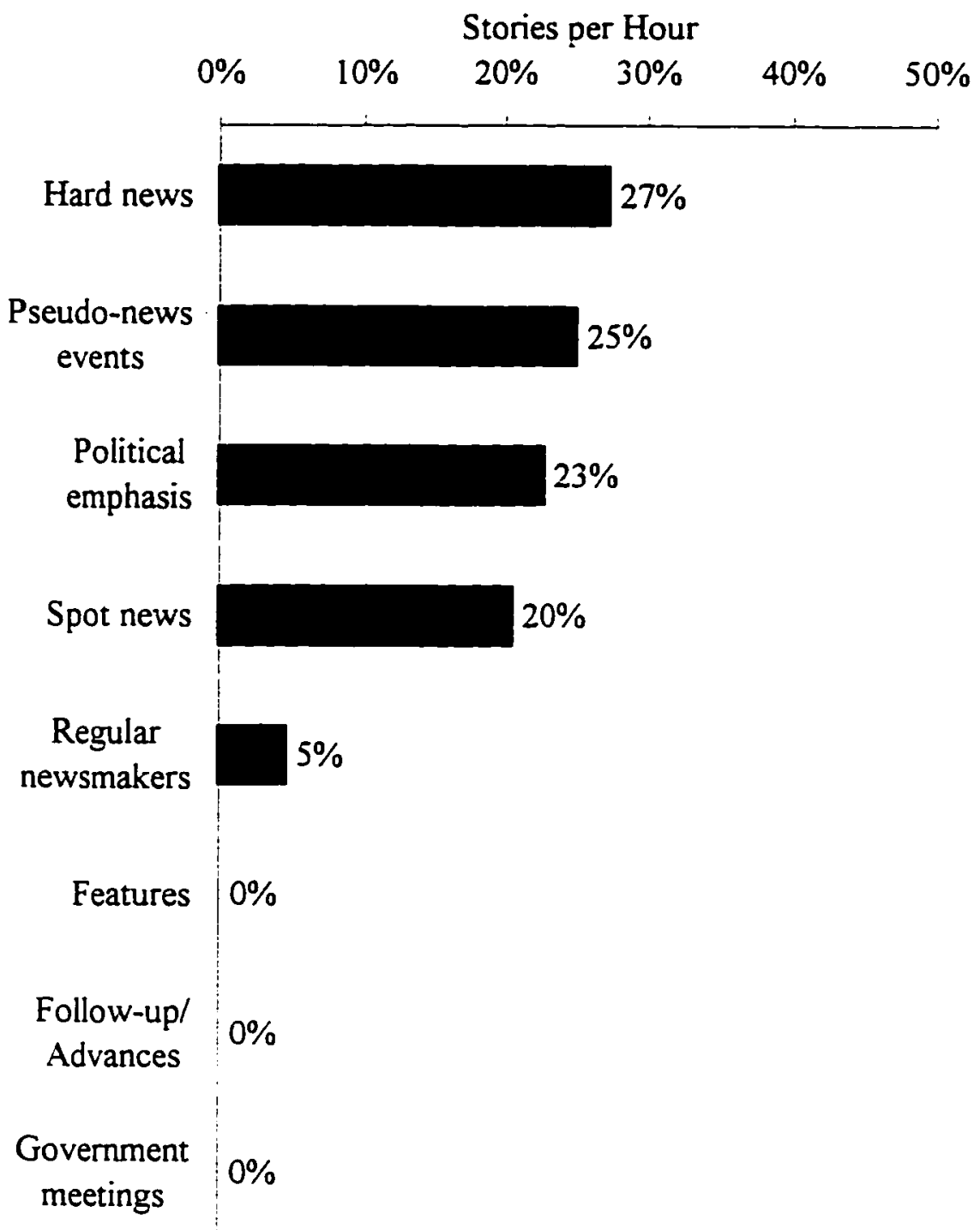


Figure 5

KMIPH Noon Drive Time 12 p.m. - I p.m. on April 10, 1995

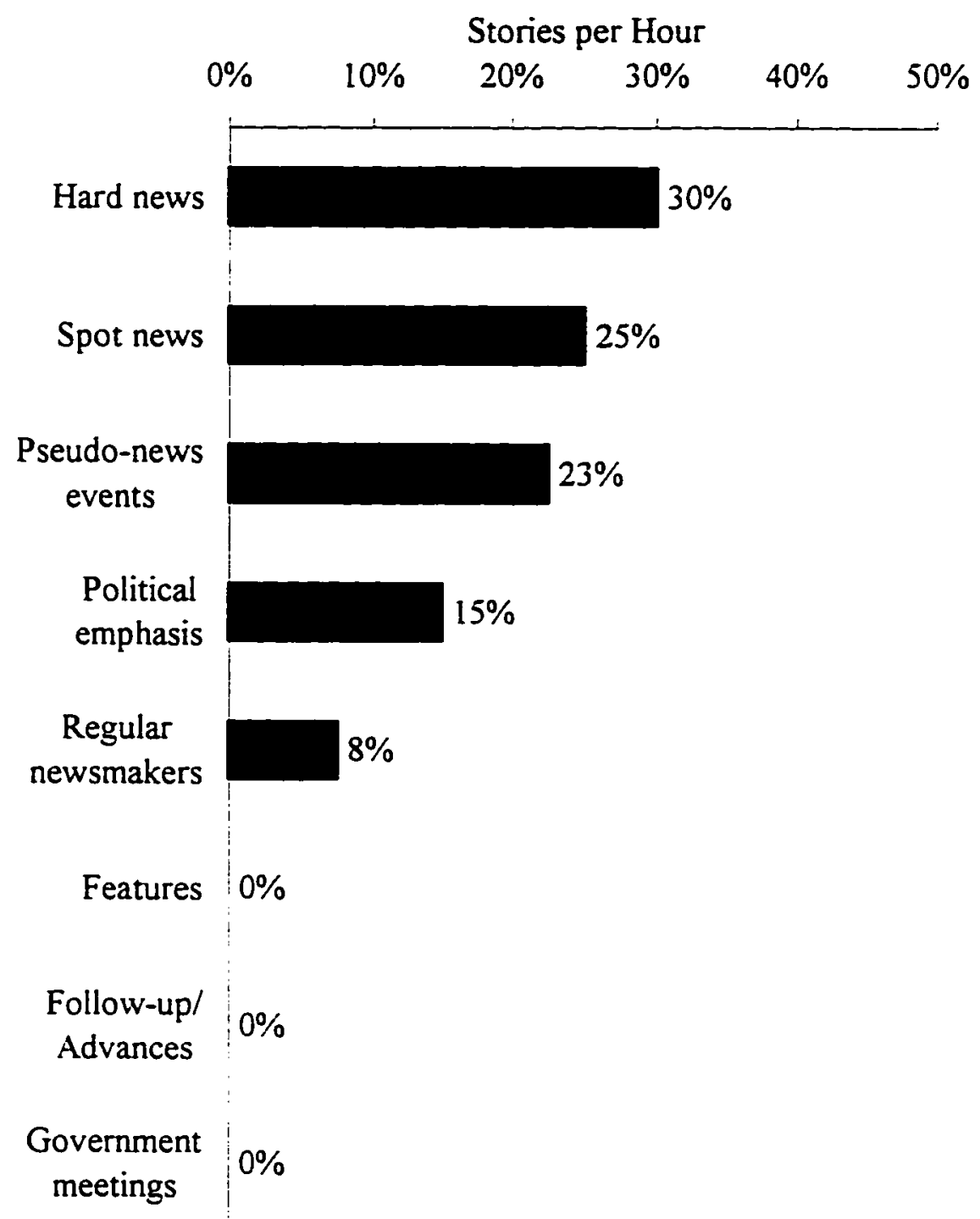




\section{Figure 6}

KMPH Afternoon Drive Time 5 p.m. - 6 p.m. on April 14, 1995

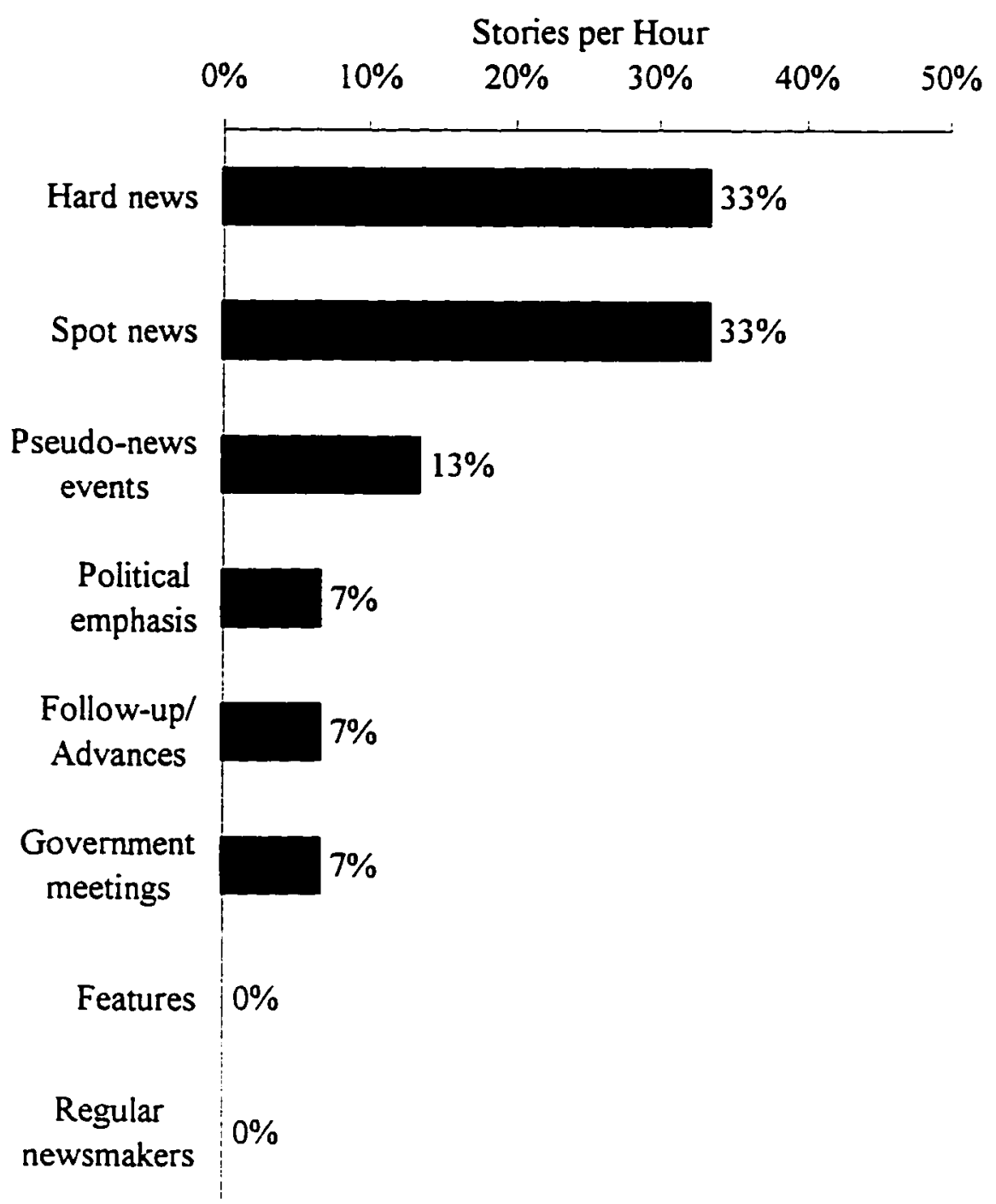


In an analysis of the stories aired during the observation period, it was noted that KCBS did a better job than KMPH of developing more depth and context in its stories. Throughout the day, the KCBS anchors conduct live phone interviews that last anywhere from three to five minutes. The subject matter varies from a follow-up on a hard news story to the development of context surrounding an item or event of interest for that day. An example of how a journalist developed a story beyond the superficial level took place in the spring of 1996 when KCBS Anchor Lois Malconian traveled to Bosnia to talk with the people of this war-torn country. She did several in-depth live reports from Bosnia as well as a series of smaller stories upon her return. Because the station provided time for all of these reports, listeners were better able to relate to the people who have suffered during the years of war in Bosnia in recent years. In contrast, KMPH has a heavy reliance on crime follow-up stories and stories that emanate from news conferences or news releases. It is also noteworthy that nearly every story was written in a simplistic fashion rather than with depth and context. This simplistic style fits into the routine of radio as headline media. Fallows (1996) wrote that such simplistic coverage leaves the audience feeling little connection with the world around them.

\section{Institutional Influences}

\section{Resources}

The money available to each station is limited but for different reasons. The KCBS budget had been impacted by the need to cover two major floods during January and March of 1995, and an organizational decision to provide in-depth analysis of the O.J. Simpson trial. Berkowitz (1991) found reporters who felt their personal news judgment 
was important to how a story should be covered. However, the resources of the organization were a priority and, therefore, budgetary issues became a constraint. One KCBS reporter (1995) commented that the cconomic constraint had become a highcr priority than in the past and was affecting the individual reporters: "It's worse than it's ever been. Bottom line journalism is what it is. Cover what you can and you're lucky you do. There's no question about it. They're trying to save money. CBS is looking to get sold." This reporter's frustration is indicative of a journalist who wants to get off the assembly line and is being forced to stay. One of the KCBS managing editors noted that one response to the tight budget was limiting the use of per diem staff when full-time reporters were on vacation. Todd Smoot (1995) said the goal was to provide a news product the audience would not detect was put together by a minimal staff. However, Smoot said quality can be affected: "We are supposed to be a profit-making business, and that doesn't affect our news product except when we have to control expenses." Berkowitz (1991) found when a media organization tries to balance the financial reality with the goals of journalism. McManus (1992) noted that this conflict results in a high concentration of human interest and emotional stories.

The investment in technology at KCBS is overdue according to staff who are frustrated with the limitations of the current station's computer system. A major limitation is the absence of any archives. This would add to the ability of the station to provide context and accuracy to stories. One editor (1995) noted it would have been great to pull up Al Davis' comments about Oakland several years ago and contrast them with 1995 comments upon the return of the Raiders to Oakland. The general manager (1995) 
maintained there are resources available outside the station including newspaper morgues, libraries, and computer data bases. However, Frank Oxarart did agree it was time to update the system.

Although KMPH has a digital computerized newsroom, the staff doesn't use all of what is available to them because their stories are normally just cursory reviews of events. The investment in the computer hardware is not supported by subscription to various databases which are themselves quite expensive. Although the staff is working with state of the art technology, it results in two problems. The new technology does break down, regularly during the first few months on the air, and few engineers who understand the system are available to make repairs quickly. This delay results in extreme stress for the staff as they scramble to print out news from the wire services to keep themselves on the air. Quality of content drops off, but the news director (1995) said they have developed a system to carry everything live, and that the stress is lessening. The second issue concerning technology that affects the quality of news content is the financial decision made by the corporation to pay minimal salaries. The start-up costs were so substantial, according to the news director (1995), that the salary allotment had to be limited. Angela Ehigiator said: "Resources are a tremendous constraint. Because so much money has been invested into this station equipment-wise, millions of dollars, and there have been times where it has come up in conversations I have overheard that the equipment is really nice, and it's really nice to have this advanced system even though it is still experimental for the industry. Gee, wouldn't it be nice if we could get more money per hour if this much money hadn't been invested, and what I say to them is be grateful for this experience 
you're getting, because it is going to be state of the art." The result of low salaries is an inexperienced staff and limited quality in news content.

Competition

Sigal (1973) wrote that journalists, in a herd mentality, race to cover what the competition is covering. This routine practice gives way to a loss of innovative and creative coverage. In all of the interviews conducted for this study, the concept of competition was seen as a positive force for the industry. KCBS News Director Ed Cavenero said: "If you're by yourself and don't have any competition, I think people can actually get complacent and lackadaisical, and I think competition helps that way" (1995). Strictly based on format, most journalists at KCBS don't believe they have any true competition in their market, because they are the only all-news radio station. Anchor Mike Pulsipher (1995) said his experience has been that management tends to put more resources into a newsroom when there is a legitimate competitor. When KPIX Newsradio first went on the air in San Francisco, there was some concern. However, KCBS staff people felt that KPIX was so bad that it was not a serious threat (1995).

KMPH, however, is the smaller station in a market in which a newstalk station is number one in the ratings. KMPH General Manager James Rowtan (1995) said KMJ was direct competition even though KMPH was an all-news station: "I saw some weakness in their inability to accurately and impartially deliver the local news on the radio. We saw them doing a lot of editorializing. We saw them putting little emphasis, less emphasis on the local news as their success with their syndicated programming began to grow." The general managers at KCBS and KMPH focused on ratings and, when asked about 
competition, Rowtan noted: "That's the reality of this business; it's ratings driven." It is clear that KMPH is much more concerned about survival based on ratings points than KCBS (which is already rated number one in cumulative or total listencrs in the market according to Arbitron surveys).

Few of the journalists interviewed in this study accepted Sigal's idea that reporters race to cover what the competition is following (1973). Although KCBS reporters and editors recognize the excitement in getting a story on the air first, most balance that by saying the important point is to get the story right. One reporter (1995) said he would never risk his reputation by doing a sloppy job just to get the story on the air. There was also a lot of discussion about special feature stories and documentaries that really set the stations apart from the competition, but during the observation periods there were no documentaries and few feature stories. At KCBS, it was clear the decision had been made at the organizational level to use the two primary feature reporters as fill ins for other vacationing staff members, and they could not be used for outside creative or in-depth pieces.

Sigal (1973) noted one routine used to keep competitive is to listen to what the other stations are covering. As far as monitoring other media, both stations have televisions running at all times. KMPH staff people have more of an organizational routine of watching the television newscasts and bringing their coverage into newsroom discussions. KMPH News Director Angela Ehigiator justified monitoring other media: "You need to be aware of what everyone else is doing. They're angles on stories that sometimes you see another station take and you go 'Oh' and you may not necessarily do 
that same story that way, but it gives you a different perspective" (1995). The use of newspapers as a resource for story ideas is prevalent at both KCBS and KMPH. Staff peopie indicate they use the papers as a resource and do not consider them competition (1995). However, on a number of occasions, stories were assigned out of the paper. This was especially true for the early morning reporters to ensure that stories got on the air during the morning drive time. KCBS Assignment Editor Dory Culver (1995) said using the newspaper can be an ethical problem: "It's a problem for me if it's their source material and we have no independent knowledge of the story to use it entirely." Although both stations discuss giving credit to the newspapers, it is rarely done. Personnel at both stations talk about innovative reporting, but the vast majority of news stories are repeated throughout the media. The choices at both stations also followed McDonald's (1978) observation that, for something to be considered newsworthy, there must be some kind of event or happening.

\section{Sensationalism}

Styles of reporting the news and the criteria for a news story at the institutional level have changed throughout the years. In the 1970 s infotainment became popular and is still seen in newsrooms today. A higher priority is put on stories that involve crime, disaster, or sexual scandals and encourages the news anchors to have casual conversation with each other while on the air. The variety of tabloid newspapers and television shows make no attempt to stay clear of sensationalism in their writing, but in combination with the concept of infotainment, they have had an effect on the mainstream press. At KCBS, the staff commented on changes in news content that have occurred in recent years. The 
news director (1995) said the organization used to consider itself the station of record, and it used to try to cover all of the news in the Bay Area. Today, there is a younger staff in terms of age, and these individual reporters have fresh ideas. As News Director Ed Cavenero noted, the assignment editor and reporters are looking for stories that impact people and that allow reporters to develop some kind of texture. By this, he means a story that can use natural sound, creative writing, and various voice cuts so that a listener feels more a part of the story as opposed to being an outsider.

The only two examples of sensationalism observed during this project involved famous people in trouble with the law. The first was truly sensational because it had no real impact on the audience, a factor that staff members had earlier indicated was a prerequisite for a story to be newsworthy. The story was the arrest of actor Hugh Grant in the company of a prostitute in Los Angeles. In talking with the KCBS staff, most reporters and anchors had the impression the story was covered only a few times throughout the day of the arrest (1995). In reality, the story played every hour and included two live interviews; one with the station's movie critic and one with a radio station in London. Managing Editor Todd Smoot (1995) responded: "There is some validity to the fact that what people want to hear is news." Because the Grant story was the talk around the station and elsewhere for days. One reporter (1995) said the station would have been remiss to ignore the story. This is an example of how competition with other media may have resulted in journalists crossing their own ethical boundaries to meet the organizational expectation to cover a story that everybody is talking about. Steele (1987) wrote that this kind of pressure makes it difficult for reporters to follow ethical 
values and may actually cut into the quality of news content.

The second example of sensationalism involved the coverage of the $\mathrm{O}$. J. Simpson murder trial. Both news stations had to make a decision on the level of coverage that would be afforded this trial. KCBS chose to assign two reporters fulltime to share the duty of listening to the gavel-to-gavel coverage and doing four updates an hour while court was in session. KMPH chose to run the trial live.

KCBS managing editor Todd Smoot (1995) said that, although the Simpson case was full of gossip and sensationalism, the station's goal was to bring depth to the story and show how it may have an impact on other people's lives. Through news coverage of this case, the audience could learn about the legal system, discuss whether the system is fair to African Americans or the poor, and become more aware of crime in general, including murder and spousal abuse. The critical question is whether four updates an hour for nine months was necessary to meet those goals or whether the sensational aspects of the case played a larger role in the decision-making than journalists are willing to admit. Assignment Editor Dory Culver (1995) said she personally didn't need to hear so many updates, but she believed the listeners wanted the extended coverage. News Director Ed Cavenero (1995) said the format of the station is designed so that listeners can tune in and within 10 or 15 minutes have a feeling of being up to date on the major stories. The Simpson updates every 15 minutes certainly fit with that criteria, but most other major stories only ran once an hour with maybe a mention in a headline at the bottom of the hour.

KMPH News Director Angela Ehigiator (1995) said the decision to go with full 
coverage was difficult, but she didn't believe the polls that indicated people were sick of the story. She felt they made a win-win decision because people who didn't want to listen to the Simpson triai could stiil tune in for the morning and afternoon drive times, which was normally before and after the court day. She also believed that new listeners were tuning in for the trial coverage and sticking around to hear their newsblocks as well. The KMPH decision was more of a business decision than a journalistic decision. It was hoped that the ratings would climb and that the new listeners would stay with the station after the trial ended. Ehigiator also said it allowed the station to experiment with some form of long programming rather than the all-news format in case a decision in the future pushed for a format change.

\section{Organizational Influences}

\section{Format}

Whitney (1987) wrote that news organizations shy away from innovation to maintain control in the market. Both stations use proven formats although different from one another. KCBS repeats its lead stories every hour. The lead national story may be repeated at the bottom of the hour, but otherwise, only breaking news is repeated within that hour. An exception was the decision to carry live updates on the O.J. Simpson trial four times an hour when court was in session. The hour includes traffic and weather updates every 10 minutes, sports twice an hour, and business twice an hour. This leaves two large news sections of about five minutes each and two smaller news sections of about three minutes. To bring a fresh touch to each hour, an attempt is made to do a live telephone interview, usually taking up one of the smaller news sections. The format for 
story length and style falls into a pattern just as the final product is dropped off a factory's assembly line. The general manager for KCBS, Frank Oxarart (1995), discussed his desire to see more in-depth coverage of issues. He aiso suggested adjusting the format to ailow for longer, more complex stories. Oxarart said that some stories never made it to air because time was running out, but he suggested that anchors, editors, and reporters should do more innovative planning. Oxarart noted that the entire story doesn't have to always be aired as a single unit. He suggested that, when a story warrants being longer than one minute, editors could adjust the format so that only half the story is played. The anchor could then tease the second half of the story, play a commercial, and then finish playing the rest of the story.

At KMPH there is more repetition with lead local stories being repeated every half hour as well as a mirroring of the national news at the bottom of the hour. KMPH has substantially fewer reporters who are responsible for producing stories. Therefore, there are fewer local stories available to fill the news hour at KMPH. The station's management made the decision to carry the O.J. Simpson trial in its entirety. Even during the trial coverage, the anchors, editors, and reporters continued to produce news stories so that, when the trial adjourned, they could go directly into news. The newsroom took on a blatant feel of a factory during these court days. It was observed that the energy level and productivity dropped off during days when the trial was in session as compared with days when court was in recess.

Both stations' news directors (1995) maintained that the repetitious nature of the all-news format is its strength. The idea is that the listener can tune in at any given time 
and within a few minutes be aware of the major news of the day. At KCBS it appears that the constraints of the format limits the news content. Each reporter is only expected to file two stories a day, one for the afternoon and one for the morning. There were a few exceptions noted during the observation period when breaking news required a reporter to cover a third story. There were a lot of news stories, though, that were never covered. These additional stories did not have as high a priority according to the traditional views of newsworthiness; however, they did carry value, impact, and interest. These stories could have been used to freshen-up the newscast.

The repetition issue is more profound at KMPH because of the decision to mirror the local lead stories. This regularly involves four to five stories. At KMPH the writers and editors are inexperienced and are not given the opportunity to cover stories. The result is two to three people pulling together wire copy and network feeds rather than working on local news that often has a greater impact for the audience. There were many stories noted during the observation period that could have been handled by inexperienced journalists so that they would gain the training necessary to grow professionally. The dependence on network feeds and the wire service add to the factory atmosphere at KMPH. Adding a wider variety of stories would improve the quality of content.

\section{Staffing}

Staffing is an issue at both stations. Economic constraints influence the organizational decisions on staffing. These decisions ultimately lead to quality problems in the news content because journalists at the individual level can not perform at their potential (Viles, 1993). KMPH views itself as a first stop news opportunity for the 
positions of editor and writer. The inexperience of some staff members results in the reduction of quality news content. News Director Angela Ehigiator noted: "Inexperience is also a constraint. We have to go through this learning curve. It has cost us, in my opinion, in terms of the quality, the quantity, and the overall programming of the station" (1995). The problem can be divided in three categories: a) lack of general knowledge, b) lack of news judgment, and c) poor morale. Most of the inexperienced staff are college students or have only recently graduated. Examples of their lack of general knowledge included an assignment editor who was unaware that lie detector tests are almost never admissible in court. She was also unaware that the U.S. Navy includes a flight arm as well as the ships at sea. It takes time and energy to correct and educate the staff and catch the mistakes before they go on the air. Editors at KMPH are in a key position, deciding the placement of stories. However, most of the KMPH editors approach the editing process in the factory model mode. They appear to plug in stories based on the length of the story and when the story last ran. There is rarely any discussion about the importance of stories. A few examples included an armed robbery that station personnel knew about at I0 a.m. A reporter was sent out, but nothing was on the air until more than an hour later. The news director agreed this was a judgment error. Ehigiator said: "That is a writer or an editor asleep at the switch. That's the kind of thing I write memos about, that we remind people about in meetings. It just seems harder for people to latch onto the urgency and the immediacy of news" (1995). Another example involved four climbers stuck on Yosemite's El Capitan. The climbers had spent the night on the mountain, and a rescue was in the works. Even after the researcher passed on this information to the assignment 
editor, it was not assigned to a reporter. When the news director was informed by the researcher, she started delegating writers to get the story. Later that afternoon, a writer received an update that the climbers had made it off the mountain safely. His story was written and filed before the top of the hour, but the editor placed the story in the second half hour rather than as the lead coming out of the network news. The lead in that position was a story about a small drug seizure with no arrests. This story had been running every hour for the past six hours. The conflict that erupted between the editor and the writer only added to the already evident morale problem.

Frequent complaints about salary also indicate morale is low among the KMPH staff. A more subtle display of morale problems is the casual conversation at the editor's desk and a lack of motivation to go beyond expectations. Drew (1972) wrote that, when role expectation doesn't match role performance, conflict arises with one result being that the staff becomes passive. It appears the limited role of writers and editors at KMPH results in a squelching of their desire to excel. The news director commented that she trusted "very few of them to handle a story from beginning to end" (1995). The assignment editor expressed concern when writers were told to take a story from KMPHTV and rewrite it, especially if that story were complex.

There were only a few examples of this same passive response by KCBS staff. A few times a writer would offer a suggestion on a news story with no response from the editors or assignment desk (1995). One such idea was to do a comparison of the judicial format of the O.J. Simpson case with the trial of Richard Allen Davis, who was charged with the kidnapping and murder of Polly Klaas. The judge in the Davis case chose to ban 
cameras from the courtroom and not to sequester the jury. When there was no response from the assignment desk, the writer made a sarcastic comment to a fellow writer followed by a subtle complaint about comparative salaries. They both then continued with the mundane work of rewriting wire copy along the assembly line.

The major staffing constraint felt by journalists at KCBS centers on the lack of extra staff people available to be called in to replace those on vacation. Managing Editor Todd Smoot (1995) maintained the station's budget had been stretched beyond its limits because of two months of intense flood coverage and the O.J. Simpson commitment. Ed Cavenero, the news director, noted that there is a staffing level at which the quality of the news product is reduced. When that level is reached, Cavenero said per diem people are brought in: "It's where you put your resources. You can always use more people, but are you using the resources well, and does it pay for it?" (1995) Reporters and editors struggled on more than one occasion during the observation period with the lack of locally produced news because of the limited staff. In interviews (1995), the staff didn't agree the economic constraints were primarily the result of the need to cover massive winter flooding. Many mentioned the pending sale of CBS News, suggesting that the economic bottom line had to reflect a positive reading. Neither the news director nor the general manager expressed any direct concerns regarding the sale, although budgetary restrictions were mentioned by management personnel as an economic reality that had to be handled. Newsworthiness

The decision-makers at the organizational level choose which stories are to be covered, but journalists at the individual level often fall into a routine on how such stories 
are covered. Sigal (1973) wrote that reporters often go to the same newsmakers for comment on stories. These newsmakers reflect, in general, the same audience being targeted by the all-news format. If the aspects of the story fail outside the routine definitions of news, Sigal wrote that many journalists avoided the story. Sigal also wrote that information gathered that "radically violates these conventions will be subject to greater scrutiny on the desks than information which does not, and reporters may find it harder to justify its newsworthiness" (pg. 66).

In all of the interviews conducted for this study, participants were asked to define news and what makes one story more newsworthy than another. KCBS News Director Ed Cavenero (1995) indicated there is no set policy within the organization on what makes news, and staff members are encouraged to share their opinions. In general, though, he said stories should a) directly affect people and b) be interesting. Berkowitz (1990) wrote that most news chosen for broadcast falls into three categories: a) issues, b) spot news, and c) entertainment. KCBS Managing Editor Todd Smoot (1995) listed a variety of ways a story could impact people, and he noted a story had to impact a significant number of listeners to warrant consideration for coverage. These areas included: a) life and safety, b) wallet or economic issues, c) jobs, d) homes, e) family and friends lives, f) things they enjoy such as sports, entertainment, etc. Smoot said the real work of the journalist at the individual level was to make the audience see how the story affects them: "What steps can we take to make the story more understandable, put into context, so people realize that what seems to be on the surface a boring local government type of story actually carries with it issues that reach beyond the municipality or the local 
area and may be precedent setting." Fallows (1996) wrote that most journalists are too busy covering all of the urgent stories rather than those that are important (p. 134). During the observation period one exampie of a reporter going beyond the superficiai story involved the announcement of further military base closures in the Bay Area. Although the initial story about the closure date and the number of people displaced was done, a sidebar story was also assigned. A reporter was sent to another community nearby where a base had been closed several years earlier. That reporter interviewed store owners, people trying to sell their homes, and community leaders about the decline in business opportunities that resulted from the base closure. Although this may be one positive example of going beyond the typical organizational constraints and driving for depth and impact in a story, KCBS General Manager Frank Oxarart (1995) questioned whether the majority of the staff spent enough time on stories to really get all of the facts. Oxarart described each story as being part of a cobweb: "No story happens all by itself just as an isolated incident. It's connected there to a lot of other things in our lives, and that's why I think we have to look at it." Tuchman (1978) wrote that journalists focused too much on cursory coverage of lots of news events rather than in-depth coverage of one issue: "Certainly, such a practice is tempting, for the newsman wants to turn in as much copy as possible and this is accomplished more easily by skimming the surface of many stories than by digging down a potential 'blind alley' to provide intensive coverage of one event-as-news" (p. 124).

One of the organizational constraints that works against this type of in-depth reporting is time. With an all-news format, the editors are always scrambling for new and 
fresh news to feed to the anchors. Instead of reviewing station policy and looking for ways to go beyond the superficial level in covering news, Breed wrote that "their energies are channeled into getting more news" (1955, p. 331). Another constraint invoives the quality of the staff. The assignment editor at KCBS (1995) said there were certain reporters she trusted to take a story beyond the superficial level. This sentiment was expressed by several other management-level people who believed that, although all of the staff members had strengths, not all of them had the ability to do the in-depth reporting described here (1995).

There was very little in-depth coverage of day-to-day news observed at KMPH. The limited number and relative inexperience of the staff accounts for the decision to handle just the top layer of news stories. However, News Director Angela Ehigiator (1995) said KMPH tried to compensate by doing documentaries. She admitted, however, that these were an added burden: "It's a strain on the staff because of the demand of feeding the all-news radio clock to have reporters take time out to do special series reporting, but I think it can make the difference many times in people's lives." The inexperience of the KMPH staff was also noted in judgment errors on which stories were more important or newsworthy. One example involved the re-opening of a bridge along Interstate- 5 that had been washed out. The story, albeit different versions, ran for three days. At the same time, there was some intense flooding going on because of recent rains. The flooding story was never done despite the fact that it was more immediate and affected more of the local audience. A second example involved a former police officer charged with killing his wife. After several weeks, he finally took the witness stand late on 
a Tuesday afternoon. KMPH had a reporter in the courtroom, and yet, his story ran only twice during the Wednesday morning drive hours of 5 a.m. to 8 a.m.

Both KCBS and KMPH ask staff reporters for input on story ideas and how to extend them beyond the superficial layer. KMPH has daily staff meetings, and some ideas are presented. However, very few of those more in-depth ideas are actually assigned by the editor. At KCBS, the assignment editor discusses each day's assignments individually with each reporter. Although this appears to take more time, it is highly effective in furthering the communication process between the editor and the reporter. If a reporter has an idea for a story, he or she will pitch it to the assignment editor. Because it is a professional, individualized conversation, these stories more often than not do get covered. On the flip side, the assignment editor has a chance to discuss stories with the reporters, and if she feels they do not support her opinion that a story is newsworthy, she will pull it from their assignment sheet. As Dory Culver noted: "If you don't have a reporter's buy-in, it's not going to be a good story" (1995).

\section{Routines}

Although most of the journalists interviewed had a broad view of what makes a story newsworthy, the actual stories chosen at the organizational level for air by-and-large fall into the categories listed by the 1990 gatekeeping study by Drew Berkowitz. These categories are government/politics, accidents/disasters, and crime. Berkowitz also found in this study that the breaking news story also carried more weight. Because of the immediacy of radio, this certainly was the case during the observation period at KCBS. The report of an explosion and fire at a marina was inserted at the beginning of the 
newscast although very little information was available. As the story unfolded, it was clear the story was not as newsworthy as other existing stories, and it was placed lower in the line-up. At KMPH the editors wcre observed being reluctant to adjust their line-ups, but this appeared to be more a problem of inexperience. These inexperienced editors appeared more comfortable using the same lead story as the hour before unless directly instructed to make a change by the news director or the assignment editor. Both stations showed restraint in jumping on breaking stories too quickly. At KCBS, there was a report that Raiders' Owner Al Davis had had a heart attack. Although several reporters jumped on the phones contacting their sources, nothing went on the air. Eventually, it was clear that Davis had just been through a routine heart check-up, which was not a story. At KMPH reporters were following the disappearance of a nine-year-old girl several days earlier. On April 10, 1995, police reported the discovery of the body of a young girl. KMPH staff held back making a connection until law enforcement officials made their announcement.

A few organizational routines noted at KCBS and KMPH include the number of stories assigned each day, how those stories are filed, the use of advance stories, and the ideas for holiday stories. At KCBS each reporter is routinely assigned one story that will run in the afternoon and one story that will be held for the morning newscasts. Although the assignment editor indicated this was not a hard and fast rule, there was only one reporter who regularly filed more than one story a day. The idea behind this routine is to afford the reporters more time to do a better job on each story. Because of the large area to be covered by the station, bureaus are in place in strategic locations. Reporters feed 
their stories over phone lines, but they do not routinely feed their written work through the networked computer system. If a breaking story hits and a specific journalist is reporting from the scene every hour, any existing recorded stories by that reporter could simply be turned into readers for the anchors. However, because the hard copy is not routinely sent in from the bureaus, often the previous story is cut from the newscast.

It is fairly typical for news stations to run stories the day before an event. KCBS Assignment Editor Dory Culver (1995) said she really preferred to have different angles for such advance stories, but she admitted there was a lot of what she termed the "going, going, gone" type stories. Holiday story ideas can be very routine. Staffing is usually at a minimum, and for the Fourth of July this was the case at KCBS. One story idea presented to the assignment editor was to interview someone from the SPCA about frightened dogs and cats during fireworks displays. The editor quickly squelched that story because it's done every year. However, the substitute assignment editor wanted to do a gun safety story following the accidental shooting of a child by a sibling. Such a story is extremely routine following a domestic accident involving a gun. It was suggested by the participant observer that a different angle might be the psychological effect of such an accident on the four-year-old child who fired the gun. This idea was rejected, possibly because it was so different from how these types of stories have always been covered. Sigal (1973) noted that stories that fall outside the routine selection are more quickly rejected. Months later when a report was issued by a children's organization about the effect of gun violence on others besides the victim, KCBS did have a reporter do a story along these lines. 


\section{Individual Influences}

\section{Manipulation by Regular Newsmakers}

Sigal (1973) and Gans (1980) found that joumalists have developed the routine of contacting the same newsmakers for comment on news stories. Editors at KCBS (1995) admit the ease with which public relations people draw in news people. Public relations professionals know when and where to call a news conference based on the known scheduling routines of the station. Sigal (1973) and Boorstin (1971) pointed out the growth in the use of news releases and news conferences by journalists to feed the allnews format. KCBS editors said they try at the individual level to evaluate each scheduled event or pseudo-event. Sometimes a different, more newsworthy angle can be developed, or the newsmaker can be asked questions on a completely different and more newsworthy subject. During the observation period at KCBS, it was clear that the assignment editor and reporters regularly discussed and evaluated the importance of scheduled news events. There were decisions made not to cover several events, and there was more interest in pushing to develop more in-depth stories. One example involved a new program established in the libraries. Assignment Editor Dory Culver (1995) said: "I just don't want another bureaucratic story." She asked the reporter to talk to the people who would benefit from the service.

KCBS regularly used politicians to respond to news events. In many cases, the politicians make themselves available to the reporters for taped interviews and for the live shots built into the format. Using political leaders within the current power structure, Soloski (1989) wrote, resulted in the media helping to maintain the status quo. KCBS 
News Director Ed Cavenero (1995) rejected this argument and said the audience needs to know where their elected officials stand on the issues of the day: "I don't buy that at all, but it shouldn't be your only source. You want to get a different point of view." The news director also saw a danger when reporters go too far in their decisions on what is newsworthy: "The danger is, all of a sudden, you stop covering things, because you decide that this is a campaign thing; it's not a real problem or issue." Managing Editor Todd Smoot (1995) also noted that some calls from politicians are rejected. In some cases it appeared the politicians played a vital role and were, therefore, considered a necessary part of the story. An example would be the involvement of U. S. Senator Barbara Boxer in the fight to save the Presidio. Editors believed her opinions on its future and every step in the process were pertinent. Boxer's staff recognizes the power of calling newsrooms directly and offering the senator for an interview. Fallows (1996) wrote that this routine relationship between politicians and journalists actually leads to a hostile environment because reporters feel used. Many of the political stories noted during the observation period came into the newsroom through phone calls from the politicians. Some stories could have been covered with more depth and context if the journalists had researched beyond the interview with the politician. One example involved State Attorney General Dan Lundgren announcing a 900 service to check on the background of child care providers. This 900 service was passed by the state legislature which is why the assignment editor chose to use a political voice to augment the story. Rather than using Lundgren, a more contextual story would have included reactions and opinions of parents and child care providers. Gans (1980) wrote that "in American news, as in the news of all 
modern nations, the people who appear most frequently in the news are Knowns, and, for the most part, those in official positions" (p. 9). Many of the news staff interviewed expressed their awareness of a mutual manipulation; the newsmakcrs use the media for publicity, and the media use the newsmakers to fill their newscasts (1995). One reporter, Mike Sugerman, said the result could affect objectivity, especially on a more subtle level: "Especially the one you know you can trust. You sort of take their word for it, and you might not question something as hard as you would someone else or push something as hard as you might if they aren't going along with it" (1995).

There were fewer examples of the use of politicians at KMPH although a U.S. Congressman doing a town hall meeting was covered despite the fact that the subject of his visit was unclear. Governor Wilson was also used in canned audio on the re-opening of Interstate 5 following the rebuilding of a bridge destroyed by flooding. The news director maintained this was an opportunity for a variety of sound. She didn't agree that there was political manipulation involved despite the fact that Wilson was planning a presidential bid. KMPH News Director Angela Ehigiator said: "It was just about the highway, so I didn't have a problem with it." (1995). Regarding pseudo-news events or pre-scheduled news conferences, Ehigiator discussed the need to cover as much of the news as possible: "Although we can be selective on whose news conferences we attend, we have an obligation to give the San Joaquin Valley a sense of everything that's happening as much as possible without putting ourselves in the position of being overly manipulated. That's a fine line." (1995). During the observation period several news conferences were missed because of staffing limitations at KMPH, although they were 
initially on the assignment sheet. It would appear that although the stories were considered by the assignment desk to be important enough to cover, the constraints of staffing levels made it impossible to develop the story.

\section{Objectivity/Accuracy}

One of the most often cited complaints against journalists is that they have a bias or slant in the way they approach and cover a story. Fallows (1995) wrote that, until reporters stop being so defensive about such remarks and truly take a look at their industry, they will continue to lose the respect of the general public. Tuchman (1972) wrote that journalists routinize their work to protect themselves against charges of bias. However, at KCBS some journalists are encouraged to be creative and interpretive. Although the assignment editor noted that she was not comfortable with every reporter making interpretations of news events, she totally trusted others (1995). Mike Sugerman is one of those allowed and, in fact, encouraged to include his opinion within a story. The goal is to put the story into context for the listener rather than to sway the listener in a certain direction of thought. Sugerman (1995) said it was appropriate and worthwhile as long as the reporter had the background knowledge to make such interpretations. There is not as much of this in the day-to-day reporting at KMPH, possibly because of the experience level of the staff. The KMPH news director (1995) indicated there was more personal interpretation done within the news documentaries, but none of these was aired during the observation period. This lack of experience at KMPH results in stories with limited depth and context, which is a form of inaccuracy, as well as, simple errors in accurate reporting. This is an example of an organizational constraint penetrating to the 
individual level. General Manager James Rowtan said: "This is the nature of the people we have to employ. When I say have to, it's because no matter what, this is a commercial radio station, and economics plays a big part . . we have to control costs wherever we can. That reflects sometimes in the quality of people we are able to hire" (1995). By using inexperienced staff, KMPH management restricts the ability of the organization to better handle the high-speed flow of news and provide an accurate representation of the day's events.

Within the organizational structure of the industry, reporters struggle with constraints that affect their ability to be accurate. Deadline pressure is evident throughout the day at both all-news stations. When a reporter doesn't even have time to write out the story, there is obviously not enough time to consider if he or she is presenting the facts in context (Whitney, 1971). During these intense deadline moments, reporters were noted falling back on the same line or angle as previous stories on the issue. One example at KCBS involved a fatal shooting and a call for more regulation on weapons. The reporter covering the story had only the pro-gun control side of the issue, and the news director pulled the story off the air until the other side could be covered. In an effort to get the story back on the air quickly, a managing editor called the National Rifle Association and did a brief interview. He wrote a generic story to run behind the reporter's story to, in effect, give balance and accuracy. In reality though, the NRA story was so routine and dry that it didn't even provide a reference to the specific issue at hand. This could have been an opportunity to follow Barret's (1982) position that there are three sides to such stories. The third side gives the context and reality of the story. 
Within the format of both stations, there are constraints with the amount of news space available. Limiting space routinely can affect the accuracy of the stories being presented. Although KCBS personnel (1995) talked about regularly allowing certain reporters to write longer stories running two to three minutes, there were few of these noted during the observation period. This could have been related to yet another organizational constraint. The feature reporters were being used to fill in for those on vacation, and they were not available to do the more in-depth pieces. At both stations, the format design calls for stories to be less than one minute long. This allows for a fastpaced newscast with lots of sound and texture; however, it loses the ability to be as accurate as possible on stories that are more complex. This adds to the habit of choosing more simplistic stories rather than those that will require more time to cover and will require more air time. An example at KCBS that took place outside the observation period involved the federal government's decision to ship nuclear waste through the Concord Weapons Station on its way to Idaho. The station ran a straight story about the decision and a follow-up story in which a reporter talked to people living in a nearby community. This again is a routinely used angle on such a story; the station wanted to get reaction from the people directly affected. However, a broader, more complicated, and ultimately more accurate story would have been to find out about the real danger of the nuclear waste coming through, the safety precautions taken, and what people can do to protect themselves.

At both stations, journalists rely on other news sources for information and are limited in their time and ability to check-up on the facts. An example at KCBS involved a 
spontaneous phone interview with O. J. Simpson on CNN in the Winter of 1996 . Because this event took place outside the observation period, it is not known whether the KCBS story was written in house or whether the story was taken off the Associated Press wire service. However, as the story was presented, the anchor reported that Simpson said he had no idea how the victims' blood got in his car. The truth is Simpson went on to give a lengthy answer accusing the Los Angeles Police Department of planting the blood evidence. For whatever reason or combination of reasons, the KCBS story was inaccurate. Sigal (1973) wrote that organizational constraints such as deadline pressure or the routine of using wire copy without checking for accuracy affects the professionalism of the journalist. During the observation periods, both stations had examples of headlines throughout the news hour that were somewhat inaccurate because writers were in charge of developing these rather than the reporter who was doing the story. In some cases, the stories themselves were not available to the writer to assist in determining an accurate headline, and deadline pressure was always a factor.

\section{Changes Since the Observation Period}

There have been substantial changes at both stations since the observation period. KCBS was part of the sale of CBS to Westinghouse in the Fall of 1995 . No substantial changes in format have taken place although some personnel changes were made. A new female reporter/anchor was added to the staff, Patty Rising. The mid-day anchor position was switched from Bob Price to Rebecca Corral. Corral was one of two reporters highlighted for her ability to cover features and in-depth pieces. Her focus now is on anchoring, although she still does news and feature stories. As far as competition is 
concerned, KPIX television and radio news are now sister stations to KCBS. The two stations sometimes work cooperatively in covering the news, and the KCBS radio operations will be moving to the KPLX studios by the cnd of 1997.

Changes at KMPH have been more substantial. During the summer of 1995, the station owner came very close to shutting down the station. The station is still on the air, but there have been major changes in personnel and format. The general manager and the news director for the radio station resigned, and their counterparts from the television side have taken over. There is one assignment editor for both stations. Several writers and editors were laid-off as the weekend format changed from local programming to AP Radio News with some local cut-ins. During the week, the format has been changed to a newstalk style with local and syndicated programming. The owners have purchased KFRE-AM and are simulcasting the news program on both the FM and AM bands. 


\section{CHAPTER V}

\section{CONCLUSION}

\section{Overview of Findings}

The goal of this research was to identify the organizational constraints that affect the broadcast journalist and the ultimate quality of the news content in radio. The various constraints identified fit into the theoretical framework describing a newsroom as a factory (Bantz, McCorkle, \& Baade, 1980). Two all-news radio stations, KCBS in San Francisco and KMPH in Fresno, were observed in the spring and summer of 1995 . Bantz et al. wrote that journalists working for broadcast news operations have many of the same characteristics as assembly line workers in a factory. Broadcast news stations have the same economic and organizational pressures, and these force the routinization of news. There were some similarities between the two stations in how they fit within the factory model, but there were examples of journalistic work that fell outside the framework. These examples involved journalists using innovation and creativity in their news coverage. Journalists often believe management personnel view them as assembly line workers along the pathway for the development and dissemination of news. This attitude produces morale problems and a lack of diversity of news content. A major focus of this study was on the decision-making process and many of the findings involve the people responsible for choosing the news content. The study included a content analysis of three hours of news from each station. Stories were categorized into these eight areas:

1. Hard news such as economics, health and safety, and politics. 
2. Feature stories such as a new way to track the location of 911 calls from cellular phones.

3. Emp̧hasis on political news because newsmakers are considered reliable An example of this could be the reaction of the mayor to block grant funding from the federal government.

4. Pseudo-news events such as stories developed at news conferences or through news releases.

5. Spot news, crime, or disaster coverage such as a plane crash, fire, or earthquake.

6. Use of follow-up or advance stories to fill the news hour and for competitive purposes. These are preview stories of an event that will be covered in the near future or a follow-up story of an event covered in the recent past. This may include stories about a trial set to begin or the visit of the U. S. President.

7. Use of regular newsmakers other than politicians such as an attorney for legal analysis.

8. Regularly scheduled governmental meetings such as city council or county supervisors.

The factory atmosphere was evident at both KCBS and KMPH, but how the individual journalists handled the various constraints placed upon them differed. In general, there were more examples of KCBS reporters and editors stretching beyond the assembly-line scenario and providing more creative and in-depth coverage of issues. However, organizational constraints limited the quality of news content at both stations. 


\section{Institutional Influences}

\section{Resources}

The business side of running a broadcast news operations was clearly felt at both $\mathrm{KMPH}$ and KCBS. Because KCBS was part of the entire CBS package up for sale, the reporters felt the budget may have been a stronger consideration for management when making decisions on whether to cover certain news events or whether to bring in extra news people. One reporter interviewed said it was a case of getting as much as one could on a story and being happy with that. KCBS journalists understood what they were missing because of resource constraints; however, KMPH staff, in general, didn't seem to recognize there were more complicated and important news stories that never hit their

assignment sheets. For example, KMPH reporters were constantly covering crime stories but rarely developed news analysis of the root causes of crime, or trends in the Fresno area. It should be noted that during the observation period, a reporter at KMPH was working on a documentary on child abuse.

Two of the top financial issues for broadcast journalism are technology and talent. The most accomplished journalists are going to cost the station more money. It was interesting to note that KCBS had invested in talent, while KMPH had invested in technology. Since the observation period, KCBS has been purchased by Westinghouse, and the staff will be moving to KPIX Television studios with a new digital news operation. Although KCBS is moving in the direction of investing in both technology and talent, KMPH has reduced its staff, including some of the more talented members. 


\section{Competition}

Although KCBS personnel did not point to any one major competitor in the market, the staff has a sense of a built-in competitive mode. Most staff people said they believed the competitive spirit encouraged them to provide higher quality news broadcasts. Certainly, whenever there was a breaking news story, reporters at KCBS jumped into high speed, almost like an instinctive response. The same high energy and enthusiasm was not evident for the more complex stories. Because the more substantive issues are usually within the more complex stories, it doesn't appear that competition plays a significant role in the coverage of these types of stories. Therefore, the competitive spirit is alive and strong in the coverage of spot news rather than in the coverage of more newsworthy events. Staff at KMPH clearly pointed to the more powerful news-talk station in the market $(\mathrm{KMJ})$ as their rival. The focus of the competitive edge at KMPH appears to rest on getting the story on the air first, although during interviews, staff also discussed the quality of the product as something to be compared to that of KMJ. Unfortunately, the quality of the news content at the competing station is lacking; therefore, KMPH staff hardly set high standards for themselves by comparing KMPH to KMJ.

\section{Sensationalism}

Examples of sensational news stories were observed at both stations. Through previous gatekeeper studies, it was noted that editors are drawn to stories that appear multiple times on several media sources. If the same story crosses the wire twice an hour, makes the network feed, and airs on national television, it is likely to be viewed as 
important by the editors. Because people are talking about the event, some would say that further justifies it as important. The best example involved the arrest of actor Hugh Grant after he was arrested for hiring a prostitute. Although stories about Hollywood people are interesting or titillating, they have little or no impact on the lives of the audience. The KCBS journalists asked about this story were surprised to hear the story had run every hour and included two live interviews. This appears to be the kind of coverage afforded a lead story rather than an interesting feature to drop in now and then. Sensationalism has become a problem within the broadcast industry and, although some stations are better than others at controlling it, the deeper issue of identifying and using important stories instead of sensational ones still must be addressed.

\section{Organizational Influences}

Format

The two all-news radio stations observed provide news to different-sized markets. KCBS serves a nine-county area surrounding San Francisco. Its signal actually reaches all of northern California. A the time of this study, KCBS was rated number one in the market for cumulative or total listeners and rated number two for quarter-hour listeners or those who tune in for more than 15 minutes at a time. KMPH serves central California with a signal that is designed to travel north and south along Highway 99 from Merced to Bakersfield although there are areas where the KMPH signal is completely drowned out by other stations. It is located on the FM band, which is unusual for an all-news format. KMPH is a relative newcomer to the Fresno market, having provided the all-news format 
for about two years prior to the observation period.

Broadcast journalists are surrounded by information throughout their workday; however, much of this news is in a headiine format. The assembiy line for such a format is moving very fast, which makes it difficult to develop very much depth on any given story. The all-news format used at both stations is designed so that there are several sections of news lasting anywhere from two to eight minutes. The majority of stories at KCBS were written and recorded by reporters, and each story ran about one minute. Story length at KMPH varied more because there were fewer reporters, and the stories covered were less complicated. Both stations have the advantage of an all-news format, and management at both stations discussed the value of news documentaries and special reports. However, there were no variations from the routine news format during the observation period. KCBS uses live telephone interviews to examine some stories in more detail, but the subjects chosen for those interviews during the observation period were not always issues of importance. Some of these interviews were conducted because the person being interviewed was available at the appropriate point in the news hour. The daily demands of an all-news format put such a time constraint on reporters and editors that they have little time and energy left to develop substantial issues into in-depth stories.

The issue of repetition came up in discussions on the format restrictions at both stations. Editors at the two stations handled this constraint differently. KMPH editors always felt they had enough news because they were constantly plugging in wire copy and national news feeds, as well as the second and third versions of the day's lead stories. At $\mathrm{KMPH}$, some of the less important news could be dumped if there were a particularly 
fruitful local news day. At KCBS, the editors struggled every day. They complained that, at times, there were so many good stories that they couldn't fit them in because of the built-in restrictions of the format. These might include a two-minute business report or a four-minute syndicated program. However, when the reporters were having difficulty providing enough stories, or when there were a large number of reporters on vacation, the editors were frustrated as they tried to fill the hours with meaningful news. The editors at KCBS really held off plugging in superfluous network feeds or wire copy, although at times there were stories on the air that didn't carry the same newsworthy components. KMPH editors did not demonstrate this same concern for the newsworthiness of wire copy or network feeds. KCBS is able to provide a greater number of stories within a given news hour because the editors only repeat two or three of the lead stories within that hour. The stories are also highlighted in the headlines and recaps. However, KMPH frequently repeats several stories from the first news flow or section. These same stories, although different versions, run in the third flow. These flows appear one-half hour apart, and these stories are also highlighted in the headlines. The repetitive format and the routine coverage of news dealing with simplistic issues and conflict follow the factory model. Repetition is one of the results of a restrictive format and limited staffing. Staffing

The KCBS staff is large with more than 50 people involved in developing the news programs. This includes a news director, dual managing editors, one of whom serves as the assignment editor, dual editors during morning, midday, and afternoon drives, dual anchors for morning and afternoon drives and single anchors around the clock, four 
bureau reporters around the Bay Area, a half dozen reporters, and writers and tape editors around the clock. The station also uses stringer reporters outside the Bay Area, sports, traffic, weather, and business reporters, and syndicated national programming from CBS. KMPH staffing has changed substantially since the observation period with quite a few layoffs. During the spring of $1995, \mathrm{KMPH}$ personnel included the news director, a managing editor, an assignment editor (shared with the television side), single editors around the clock, dual anchors during morning drive and single anchors around the clock. four reporters, and a writer/tape editor. KMPH also has weather, traffic, business, sports, and agricultural reporters, as well as syndicated programming from CBS. At the time of the study, KMPH was struggling to survive in the Fresno market with a relatively low rating of between a two and three percentage point share. Since the observation period. the owner has purchased an AM station in Fresno, and news is being simulcast on these two stations.

Both stations can be plugged into the factory model theory, although it is clear the KCBS staff has more experience jumping out of the assembly line mode whenever a major story breaks. Again, it is understandable how the daily grind of feeding the all-news format results in news development in the style of factory production. The concern is how this grind affects the journalists. There is clearly a morale problem at KMPH because getting the news on the air has become a somewhat boring daily event. Coupled with the lack of opportunity to try their hands at other aspects of the operation, in essence, to change places on the assembly line, the least experienced staff members have become disheartened and, therefore, less willing to learn. Inexperience is not part of the problem 
at KCBS, although it is clear the writers and tape editors are bored. It is difficult for journalists to feel their work is important when much of it is never used on the air but, rather, comes off the assembly line and simply sits at the editor's desk. A slight adjustment to the daily schedule for these journalists could include generating a story on their own. These could then be used to add diversity to the news content, especially on weekends and Monday mornings. Such minor adjustments that encourage all journalists to go beyond the daily production would open minds, increase story counts, and provide a way for each reporter to grow professionally.

Although the editors at KCBS run the desk for eight hours, their counterparts at KMPH switch off every hour with the writer/tape editors. By switching off every hour, the editors at KMPH lose continuity with the flow of news, lose a sense for the appropriate time to change lead stories or rewrite wire stories, and lose the opportunity to become stronger and more confident in their decision-making skills.

\section{Newsworthiness}

At both KCBS and KMPH, the reporters lean heavily on the assignment desk to provide them with the story ideas and back-up information necessary to cover their daily assignments. It was noted that a few times KCBS reporters came in with story ideas that were truly original, and the daily personal conferences with the assignment editor did serve to stir the creative juices to find new and different angles from which to cover a story. Although some story ideas were tossed out during the staff meetings at KMPH, they were ignored by the assignment editor. The staff, therefore, grew less motivated to open up their minds in search of more contextual coverage of the day's events. 
Most of the information gathered during this study involved participant observation and interviews; however, a small content analysis was also conducted to review the diversity or varicty of news content. A varicty of constraints built into the factory model results in the assignment editors choosing to cover a majority of simple stories that deal with some sort of conflict rather than delve into more complex stories presented in context that would give the audience a better understanding of why the news they are hearing is important. Both stations have a heavy commitment to hard news, especially politically generated news. KMPH also had a significant percentage of spot news dealing with crime and a reliance on pseudo-news events. KCBS had a higher percentage of features and used the routine of developing advance or follow-up stories more often than KMPH.

The criteria for a newsworthy story were similar at both stations. Usually station personnel want stories to have some kind of direct impact on the listeners. In reality, there was a variety of stories aired by both stations that had very little direct impact on a large portion of the audience. Often these stories fell into the routines established by reporters and management to help run the operations. Staff at both stations were limited by management's job descriptions, in that, some tape editors indicated a desire to develop additional news stories. These additional stories may not be as high a priority according to the traditional views of newsworthiness. However, they would carry value, impact, and interest. These stories could be used to freshen-up the newscast. There is a fine line between allowing reporters ample time to completely cover an important news story and forcing journalists to cover so many stories that all are covered superficially. To improve 
the diversity of news content at KCBS, more variety of news should be injected into the format. KMPH could improve the depth of coverage by developing more in-house stories and not relying so heavily on wire services and network programming. Although both stations hold news meetings, the individual discussions between the assignment editor at KCBS and her reporters are much more interactive and result in a more varied news product. This practice has the potential to take reporters off the assembly line to discuss the importance of story assignments.

\section{Routines}

With a few exceptions, journalists and management personnel at both stations rely heavily on routines to keep the all-news format running smoothly. This is understandable. because in the ever-changing, fast-paced world of news, it is necessary to have some kind of order. However, it was when those routines became more like crutches that the quality of the news content suffered. Staff regularly looked to the newspaper as a resource and, at times, stories were assigned directly out of the paper. Another resource is a two-edged sword. News operations today are inundated with news releases about news conferences. These announcements are dropped onto the assembly line and handled routinely by the assignment editors. KCBS displayed better judgment in choosing which news conferences to attend, but the dependence on newsmakers to provide the time and place for the dissemination of information can affect the ability of the journalist to develop a truly accurate picture of the news day. The use of pseudo-news events help ease the pressure from deadlines. Deadline pressure is intense at both operations, although it appears the staff at KCBS understands the importance of immediacy more than the relatively 
inexperienced staff at KMPH. As a result, the deadline pressure is more intense at KCBS.

The depth and diversity of news coverage can be expanded if the entire news operation is involved in the development of ideas and angles for stories. This really breaks into the orderly routines to maintain the operation, but with some management orientation, it could prove to open the door to stories that are truly important to society.

\section{Individual Influences}

\section{Manipulation by Regular Newsmakers}

Newsmakers recognize the routines set in place by news organizations, and they develop their game plan around that. Journalists know this is happening, and they sometimes become cynical or adversarial toward the newsmakers. As this cycle continues, the relationship can deteriorate to a point where newsmakers withhold information. making it even more difficult for the journalist to provide depth in a story. There is a traditional role of the journalist as the watchdog, which is as it should be. But because of the manipulation by others and the journalists' acceptance (especially in radio) of simplistic coverage, the quality of news coverage has dropped. It is necessary to stand back and review how to break this cycle and, thereby, provide a better product for the audience. Although both stations had examples of using political leaders for sound bites in a story, the practice was much more evident at KCBS. Staff admitted they felt manipulated at times, but they saw this as a two-way street and the only way to quickly and effectively get the story. Fallows (1996) wrote that there is a lot of time and energy wasted as journalists try to dig up dirt on newsmakers, because the reporters are frustrated about 
being manipulated by the power structure. This lost time and energy would be better spent developing a more accurate picture of the day's news events.

\section{Objectivity/Accuracy}

The journalists at KCBS have more general knowledge that can be used in covering news assignments. Still, to really get to the truth behind a story takes an open, questioning mind and the time and desire to track down all sides of the issue. At KCBS. journalists have developed the routine of getting both sides (i.e. gun control), but the type of questioning has become so generic that the same response can be plugged into future stories on the same subject. If a journalist takes the time to study the issues of importance, then, when the time comes to question the major newsmakers, it will be possible to develop the depth and context necessary to present an accurate picture of the issue or event. It appears most of the journalists at KCBS are relying on their general knowledge and experience to guide them through, and the journalists at KMPH are lacking in both general knowledge and an understanding of the issues of the day that comes from research. Radio may continue to be headline media, but they don't have to produce superficial coverage of the news. Few examples of story depth and context were noted during the observation period at either station; however, both have had in-depth stories on the air since then. These special reports or documentaries displayed the context that is an important element of an accurate picture of any news event.

\section{Limitations of the Study}

Some of the limitations that affected this research involved access to budgetary information, previous professional relationships with some of the participants, and 
restrictions on hours of observation. Management personnel at both stations were willing to share ratings information with the researcher, but the budgets for the news operations were not released. During the interviews, some information about budgetary expenditures was provided. At both stations, there are journalists who had previously worked with the researcher. In most cases it appeared these relationships helped develop an environment of trust and comfort with the project. However, it was noted that the researcher may not have been taken as seriously by those with whom she had worked during the early years of her career. Because this study was voluntary, a few journalists chose not to be interviewed. It was also noted that, at times, news personnel would move into a private office for a discussion. It was assumed that these conversations were deliberately kept away from the researcher and other news personnel. Finally, both station managers required that management personnel be in the station whenever the researcher was working. Therefore, the observations could only be done during weekday, daytime hours.

\section{Contributions to the Literature}

This research is the first major study into all-news radio in the post-deregulation years. It uses the framework developed by Bantz, McCorkle, and Baade (1980) that described a television newsroom as a factory with reporters much like assembly line workers. This study extends the work of Bantz et al. to all-news radio. The work of other mass communication researchers has also been extended by this study. Radio has been studied and reviewed in terms of ownership and competition, deregulation, flexibility, and ratings wars. However, radio has taken a back seat to television in studies specifically examining the decision-making process and quality of news content. 
Although this study was qualitative in nature, the content analysis of news content at both KMPH and KCBS serves to expand on many of the concepts highlighted by Gans (i980) in which he compared news content between news magazines and network television news. With the exception of some of the radio features and the identification of crime victims in some of the news stories, this study extends the Gans work to these two all-news radio stations. Although the content analysis in this study is by story topic, observations noted during the study indicate that most of the people used by reporters to comment within their stories are among the "Knowns" that were identified by Gans. These would include politicians, leading governmental officials, community leaders, and major criminals. Gans also wrote that a significant percentage of news stories on television and in the news magazines were focused on conflict, an observation also made in this study for radio. Concerning how a story is covered, Gans noted that many of the more complex stories handled in documentary form were used as leads for more routine stories. This study noted repeatedly how radio reporters, because of organizational constraints, are forced to develop simplistic stories based on complex issues.

Although in past research economic constraints have been noted as they pertain to ratings, this study reflects how the external and internal economic pressures affect the decision-making process. At the organizational level, the issues of staffing limits and the availability of financial resources have become a major part of the assignment process. At the individual level, reporters are clearly aware that economic constraints, such as the pending sale of a station, result in restrictions on the financial support for their reporting work. This study has uncovered a trend in broadcast journalism. With the increased 
number of stations coming together under a single ownership, television and radio news people are fining themselves working together when once they had been competitors. KivifH TV has been in the San joaquin Valley for years, bul the owner decided in 1992 io open a sister radio station. The two staffs are sharing technology, and the expectation is that reporters and anchors on both sides will develop stories for both stations. More recently, KCBS was purchased by Westinghouse and became a sister station to its radio competitor, KPLX FM. By the end of 1997, KCBS radio will be working out of the same facility as KPIX TV and, at least, one reporter is already involved in a joint working relationship. This study has shown how the increased cost of technology and the increased capability of that technology to provide immediate news coverage, may reduce the need to have as large a number of reporters for an all-news radio station.

Other studies on television news have been expanded by this study to include radio. McManus has used his research from 1991 to write several articles and his book, Market-Driven Journalism. McManus wrote that marketing in television was the search for a large quality audience to sell to advertisers. This ratings game was evident in allnews radio as well, more so at KMPH Radio in Fresno because the KMPH management was struggling to maintain a position in the market. McManus noted the market logic was the mold for the routines that resulted in the television news selection process. Berkowitz (1990) also discussed the precarious balance between resources and news judgment. In his work with television news, Berkowitz found that story selection centered on concrete issues such as crime and disaster and usually resulted in a single story. This study has shown that in most cases radio stories are also simplistic in nature and focus on conflict 
within society. At KCBS the assignment editor usually tried to develop stories more thoroughly. This was done by assigning one story angle for the morning news and a second angle for the afternoon news.

Bailey and Lichty (1972) expanded gatekeeping research to television. It demonstrated how the organization itself becomes a series of gatekeepers. Through this study, it was found that there were fewer gatekeepers observed in action in all-news radio. Usually the assignment editor and the editor served as gatekeepers with the news director stepping in on occasion. The KCBS the assignment editor plays a strong role in laying out how the story is to be covered; however, there is much more autonomy in the field concerning the story coverage for radio reporters. This may be changing, though, with the technological moves noted above as television reporters are able to present more live coverage of news events.

Altheide (1976) discussed the issue of quality in television as well as the various factors responsible for the distortion of TV news. This study looked at the decisionmaking process and the development of news stories to expand on the factors that serve to distort radio news. These factors include such constraints as limited resources and staff, competition, sensationalism, manipulation by newsmakers, and the routinization of news. Much of the general research work on journalism can be applied to radio, but most of the purely radio discussion has been printed in trade journals rather than academic journals. This research has taken an in-depth qualitative look at the decision-making process within the organizational structure of radio news. It is designed to focus primarily on KCBS because of its standing in a major market. However, the pilot study of KMPH in a 
medium market adds another dimension to compare and contrast two stations with very similar formats.

This project also highlights the differences between specific journalists. Most research is designed to give a broad brush look at an aspect of the journalistic industry. By doing a focused study on two radio stations, it is possible to pick out the few journalists who are willing to work against the grain. In this case, it was noted that certain reporters and management personnel, at times, broke through the routines that have the potential to reduce the quality of the news content. Ettema (1982) focused on individuals in his case study on the development of an educational children's program. Ettema found that what an outsider might view as constraints on the creative side of the work actually resulted in pushing the professional to higher heights. All of the requirements of the project "interlocked into an organizational context which certainly constrained but also guided and energized the creative activity of the executive producer" (p. 103). A few journalists in this study demonstrated that some constraints can actually push them to a higher performance level. KCBS Anchor Lois Malconian (1996) didn't like the term constraint when questioned about her 10-day trip to Bosnia, but she acknowledged that the news director did help her capture the essence of why she had taken this assignment. Malconian had decided her focus for this trip would be to capture the people of Bosnia and show her audience they are very much like the people living in the Bay Area. The constraints of the radio format were adjusted to allow for five and 10-minute live interviews from Bosnia, and her coverage ran throughout the 10 days she was there. Malconian also did a five-part series upon her return. To add context and depth to her 
reporting, she researched the issues surrounding Bosnia. KCBS Journalist Mike Sugerman has been an award-winning feature reporter for years. During the observation period, he displayed his unique view of reporting news by riding his bicycle with a group that periodically rides through the streets and across the bridges of the Bay Area to protest the vast number of cars on the road. Sugerman was supplied with a portable unit that allowed him to broadcast live reports with interviews while riding alongside the other cyclists. This research found that individual journalists can and do break out of the mold of routine news coverage to produce a story of substance and creativity, and that some stations are willing to finance such noteworthy work.

\section{Future Research}

It is clear that, although certain decisions were observed in this study, as well as the organizational constraints that contributed to those decisions, future research could delve deeper into why journalists continue to make news content decisions that often contradict their own definitions of quality news. Rather than such a broad scope, another project could choose a small slate of variables for study. For instance, a researcher could follow just the coverage of crime news or sensational stories of little consequence. Although this study did involve two radio stations in two different sized markets, the focus was not one of true comparison to each other. A future study could compare like stations in different sized markets. This type of research could then be used to judge a broader range of radio news operations. It would also be interesting to compare news content quality between all-news stations and those with a newstalk format. Using this study as a stepping stone, it is clear that much more research could be done into the attitude of 
journalists toward their work and their ultimate role in society. Whether public journalism philosophy is accepted by journalists today and whether they are open to making changes within their industry would be a specific direction for future research. 


\section{REFERENCES}

Âdelsberger, Bernard (1993, January). All the news . . that's fit to speak! Quili, pp. $41-42$.

Altheide, David (1976). How TV News Distorts Events. Beverly Hills: Sage.

All the news that fits the budget (1991, September). Broadcasting, pp. 15-16.

Bagdikian, Ben H. (1992). The Media Monopoly. Boston, Mass: Beacon Press.

Bailey, George A., \& Lichty, Lawrence W. (1972). Rough justice on a Saigon street: A gatekeeper's study of NBC's Tet execution film. Journalism Quarterly, 221-229, 238

Bantz, Charles; McCorkle, Suzanne; \& Baade, Roberta (1980). The news factory. Communication Research, 7, 45-68.

Barrett, Marvin (1982). Broadcast Journalism. New York: Everest House.

Berkowitz, Dan (1990). Refining the gatekeeping metaphor for local television news. Journal of Broadcasting \& Electronic Media, 34, 55-68.

Berkowitz, Dan (1991). Assessing forces in the selection of local television news. Journal of Broadcasting \& Electronic Media, 35, 245-251.

Black, Jan (1995, July 11). [News anchor, KCBS, San Francisco]. Personal interview.

Boorstin, Daniel (1971). From news-gathering to news-making: A flood of pseudoevents. The process and effects of mass communication. Urbana, $\mathbb{L}$ : University of Illinois Press.

Breed, Warren (1955). Social control in the newsroom: A functional analysis. Social Forces, 33, 326-335.

Buckalew, James (1974). The local radio news editor as a gatekeeper. Journal of Broadcasting, 18,211-221.

Buckalew, James (1970). News elements and selection by television news editors. Journal of Broadcasting, 14, 47-54.

Cavenero, Ed (1995, June 22 and July 13). [News director, KCBS, San Francisco]. Personal interview. 
The Commission on Freedom of the Press (1947). A free and responsible press. Chicago: University of Chicago Press.

Connors, Edward (190!, May). They still call it radio news. Washington Journalism Review, pp. 39-42.

Conway, Terry (1995, June 28). [News editor, KCBS, San Francisco]. Personal interview.

Culver, Dory (1995, July 6). [Assignment editor, KCBS, San Francisco]. Personal interview.

Dozier, David M., \& Hofstetter, C. Richard (1986). Useful news, sensational news: Quality, sensationalism and local TV news. Journalism Quarterly, 63, 815-820.

Drew, Dan (1972). Roles and decision making of three television beat reporters. Journal of Broadcasting, 16, 165-173.

Ehigiator, Angela (1995, April 10 and 13). [News director, KMPH, Fresno]. Personal interview.

Ehrlich, Matthew (1992). Competition in local television news: Ritual, enactment and ideology. Mass Comm Review, 19(2), 21-26.

Eisenberg, Ira (1990, October). The selling of the news. San Francisco Focus, pp. 64$69 ; 100-102$.

Eliasoph, Nina (1988). Routines and the making of oppositional news. Critical Studies in Mass communication, 5, 313-334.

Epstein, Edward J. (1975). Between fact and fiction: The problem of journalism. New York: Vintage Books.

Epstein, Edward J. (1973). News from nowhere. New York: Random House.

Ettema, James S., \& Whitney, D. Charles (1987). Professional Mass Communicators. In Handbook of Communication Science, 747-774.

Ettema, James (1982). The organizational context of creativity: A case study from public television. Individuals in mass media organizations: Creativity and constraint. Beverly Hills: Sage. 
Fallows, James (1996). Breaking the news: How the media undermine American democracy. New York: Pantheon Books.

Gans, Herbert (1979). Deciding what's news. New York: Pantheon Books.

Griffin, Michael (1992). Looking at TV news: Strategies for research. Communication. $13,121-141$.

Gross, Peter, \& Stocking, S. Holly (1989). How do journalists think? Bloomington, IN: ERIC Clearinghouse on Reading and Communication Skills.

Halsey, Paul (1995, June 20). [News editor, KCBS, San Francisco]. Personal interview.

Hansen, Kathleen; Ward, Jean; Conners, Joan; \& Neuzil, Mark (1994). Local breaking news: Sources, technology, and news routines. Journalism Quarterly, 71, 561-571.

Humphrey, Karen (1995, April 13). [News consultant, KMPH, Fresno]. Personal interview.

lyengar, Shanto, \& Kinder, D (1987). The agenda-setting effect, news that matters. Chicago: University of Chicago Press.

Malconian, Lois (1995, June 27). [News anchor, KCBS, San Francisco]. Personal interview.

McCarthy, Abigail (1985). Is good news news? or, can hope survive the media? Commonweal, 112, 393-394.

McCombs, Maxwell, \& Shaw, Donald (1993). The evolution of agenda setting research: Twenty-five years in the marketplace of ideas. Journal of Communication. 43, 156163.

McDonald, Donald (1978). Is objectivity possible. Enduring issues in mass communication. Center Magazine, 4, pp. 29-42.

McManus, John (1994). Market-driven journalism: Let the citizen beware? Thousand Oaks: Sage.

McManus, John (1992). What kind of commodity is news? Communication Research, $19,787-885$.

McManus, John (1991). How objective is local television news? Mass Comm Review, $18(3), 21-30$. 
Miller, Scott (1995, April 12). [Assignment editor, KMPH, Fresno]. Personal interview.

Oxarart, Frank (1995, July 12). [General Manager, KCBS, San Francisco]. Personal interview.

Pulsipher, Mike (1995, July 11). [News anchor, KCBS, San Francisco]. Personal interview.

Radio's sound stands up to TV's sight. (1991, September). Broadcasting, p. 24.

Roshco, Bernard (1975). Press releases and Pulitzer prizes: The diverse meanings of "objective" news. Newsmaking. Chicago: University of Chicago Press. pp. 39-57.

Rowtan, James (1995, April 14). [General Manager, KMPH, Fresno]. Personal interview.

Shoemaker, Pamela, \& Reese, Stephen (1996). Mediating the message. New York: Longman.

Sigal, Leon (1973). Reporters and officials. Lexington, KY: D. C. Heath.

Smoot, Todd (1995, June 29). [Managing editor, KCBS, San Francisco]. Personal interview.

Snider, Paul (1967). "Mr. Gates" revisited: A 1966 version of the 1949 case study. Journalism Quarterly, 44, 419-427.

Soloski, John (1989). News reporting and professionalism: Some constraints on the reporting of the news. Media, Culture and Society, 1I, 207-228.

Steele, Robert (1987). Video ethics: The dilemma of value balancing. Journal of Mass Media Ethics, 2(2), 7-17.

Sugerman, Mike (1995, July 7). [Reporter, KCBS, San Francisco]. Personal interview.

Terronez, Stephanie (1995, April 12). [News editor, KMPH, Fresno]. Personal interview.

The expanding universe of radio networks. (1990, February). Broadcasting, pp. 37-44.

The radio news conundrum: How much is enough. (1990, September). Broadcasting, pp. 43-44. 
Tuchman, Gaye (1972). Objectivity as strategic ritual: An examination of newsmen's notions of objectivity. American Journal of Sociology, 77, 660-679.

Tuchman, Gaye (1978). Making News. New York: The Free Press.

Viles, Peter (1993, May). Radio news services stress flexibility. Broadcasting \& Cable, p. 47.

Viles, Peter (1993, October). Dan Rather blasts TV news. Broadcasting and Cable, p. 12.

Wilcox, Jerry (1995, July 10). [Reporter, KCBS, Oakland]. Personal interview.

White, David (1950). The "gate-keeper": A case study in the selection of news. Journalism Quarterly, 27, 383-396.

Whitney, D. Charles (1982). Mass communicator studies: Similarity, difference and levei of analysis. In James S. Ettema and D. Charles Whitney (Eds.), Individuals in mass media organizations: Creativity and constraint. Newbury Park, CA: Sage. 